\title{
Epistemología, literatura y género: sobre un poema de Ma de San José Salazar
}

\author{
Epistemology, literature and gender: on a poem \\ by $M^{a}$ de San José Salazar
}

\author{
Patricia Fernández Martín ${ }^{1}$ \\ Universidad Autónoma de Madrid (España)
}

Recibido: 20.06.2020

Aceptado: 06.10.2020

\section{RESUMEN}

El presente artículo busca sacar a la luz los problemas epistemológicos que entraña, desde una perspectiva de género, la selección del canon literario en que se ha tomado por «natural» la exclusión de numerosos textos femeninos. Partiendo de un concepto sociocultural de "práctica" y distinguiendo entre la científica y la literaria, se analizan dos poemas (uno de María de San José Salazar y otro de Lope de Vega) en cuya semejanza formal parece no haberse reparado. La indiferencia por el texto femenino, frente a la abrumadora tinta vertida sobre el masculino, puede encontrarse en dos grupos de razones: extradiscursivos (práctica científica) e intradiscursivos (práctica literaria). La principal conclusión apunta a que el poema de Lope de Vega es individualista, universalizante y activo, mientras que el de Salazar ofrece una correlación de categorías que permiten entender la riqueza de una propuesta vital inclusiva, en discordancia con lo que se espera de un texto desde la práctica científica históricamente patriarcal.

PALABRAS CLAVE

PRÁCTICA CIENTÍFICA, PRÁCTICA LITERARIA, MARÍA DE SAN JOSÉ SALAZAR, LOPE DE VEGA.

\begin{abstract}
The aim of this paper is to shed some light on the epistemological consequences, from a gender perspective, entailed in the literary canon, where the exclusion of countless feminine texts has been taken as «natural». I take into account a

1 Grupo de investigación Discourse Analysis and Intercultural Communication (UAM SOC PR-009). Departamento de Filologías y su Didáctica, Facultad de Formación de Profesorado y Educación.
\end{abstract}

Claridades. Revista de filosofía 13/2 (2021), pp. 119-164.

ISSN: 1889-6855 ISSN-e: 1989-3787 DL.: PM 1131-2009

Asociación para la promoción de la Filosofía y la Cultura en Málaga (FICUM) 
sociocultural concept of "practice», divided here into scientific and literary. Thus, one poem written by María de San José Salazar and another written by Lope de Vega are analytically compared, since their formal similarity seems to have been systematically ignored. The indifference towards the female text, in contrast to the overwhelming amount of studies about the male one, can be found in two groups of reasons: extradiscursive (scientific practice) and intradiscursive (literary practice). The main conclusion highlights that Lope de Vega's poem is individualistic, universalizing and active, while Salazar's offers a correlation of categories that allow us to understand the richness of an inclusive life, in disagreement with what is expected from a text composed within the patriarchal scientific practice.

\section{KEY WORDS}

\section{SCIENTIFIC PRACTICE, LITERARY PRACTICE, MARÍA DE SAN JOSÉ SALAZAR, LOPE DE VEGA.}

\section{INTRODUCCIÓN}

Ni la historia Del CONOCIMIENTO ni el conocimiento mismo son objetivos. Ambos implican una relación investigador-investigado-investigación que no puede considerarse libre de valores ${ }^{2}$. Por un lado, desprender el ser del deber ser es una forma de naturalizar una actividad que es puramente social. Por otro lado, esta esencia social, aunque no sea requerida, es incuestionable, como demuestran las críticas realizadas desde la filosofía de la ciencia de Feyerabend, Kuhn, Laudan y Lakatos ${ }^{3}$, entre otros. Toda generación de conocimiento, en tanto práctica científica, es, entonces, una práctica axiológica, esto es, un sistema dinámico compuesto por una serie de agentes, un medio en el que estos interactúan, un grupo de objetos que forman parte del medio y un conjunto de acciones estructuradas, sean

2 Cf. D. R. Olson, "Cultura escrita y objetividad: el surgimiento de la ciencia moderna», en D. R. Olson y N. Torrance (comps.), Cultura escrita y oralidad, Barcelona: Gedisa, 2013, pp. 203-222; A. Tanesini, An Introduction to Feminist Epistemologies, Oxford: Blackwell, 1999; J. Lewandowska, "(Des)alienar las voces femeninas del convento: "la celda propia" de Sor Marcela de San Félix», Itinerarios. Revista de estudios lingüísticos, literarios, históricos y antropológicos 18 (2013), 11-34.

3 Cf. J. A. Díez y C. U. Moulines, Fundamentos de Filosofía de la Ciencia, Barcelona: Ariel, 2008, pp. 325-342. 
representaciones del mundo, sean supuestos básicos ${ }^{4}$. De acuerdo con esta definición, no se puede obviar la esencia práctica de todo conocimiento, pues constituye un conjunto de interacciones entre los agentes (con sus creencias y sus principios) y sus objetos de estudio irremediablemente ancladas a un entorno sociohistórico.

Esta práctica axiológica es, por tanto, un tipo de práctica sociocultural ${ }^{5}$, entendida aquí como la acción sociocultural efectuada, en concreto, por agentes concretos en situaciones socioculturales concretas ${ }^{6}$. En otras palabras, en tanto conducta humana, toda práctica (por esencia, sociocultural) se encuentra situada espacio-temporalmente y, precisamente por esto, enlazada a un sentido intersubjetivamente contextualizado ${ }^{7}$.

4 Cf. L. Olivé, «Normas y valores en la ciencia bajo un enfoque naturalizado», Revista de Filosofía 29 (2) (2004), 44-45.

5 Cf. L. Olivé, 2004, íd.

6 Usamos siempre el término «sociocultural», en lugar de «social» o «cultural», separadamente, porque, siguiendo el concepto de cultura subyacente al libro de Ángel Díaz de Rada, Cultura, antropología y otras tonterías, Trotta, Madrid, 2010 y asumiendo el fracaso implícito de su separación, tal y como se deja entrever en el último capítulo de Adam Kuper, Cultura. La versión de los antropólogos, Barcelona, Paidós, 2001, no consideramos relevante para nuestros objetivos distinguir los elementos sociales de los elementos culturales, pues ambas categorías analíticas se encuentran perfectamente imbricadas en las prácticas humanas, que es como entendemos los diferentes productos discursivos objetos de nuestro análisis en el texto. Naturalmente, habría que incluir aquí también las otras dos dimensiones que caracterizan el ser humano, la biológica y la psicológica, pues como tal es un ser biopsicosociocultural, de acuerdo con Eugenia Ramírez Goicochea, Evolución, cultura y complejidad. La humanidad que se hace a si misma, Madrid: CERA, 2009. Nuestros intereses, no obstante, se centran exclusivamente en la dimensión sociocultural, que es la que, a nuestro juicio, más afecta a la creación y aceptación de los discursos, que es el ámbito en el que nos movemos en el artículo, en la línea del análisis pragmático, por ejemplo, de J. Verschueren, Ideology in Language Use, Cambridge: Cambridge University Press, 2013, quien no solo entiende la ideología como 'ente' inseparable de la práctica sociocultural («ideologies cannot be regarded as separable and self-contained 'entities'», p. 24) sino que también da por hecho su incuestionable nivel (socio)cognitivo ( Note that neither cognition nor society/culture can be seen as taking precedence over the other», p. 8, n. 5), en una asunción, por tanto, de toda práctica discursiva como práctica (bio)psicosociocultural.

7 Cf. V. Blanco Gallardo, «Más allá de Occidente. Lo que la Antropología puede enseñar a la Filosofía», Claridades. Revista de filosofía 2 (2010), 102-105; Á. Díaz de Rada, op. cit., 2010, pp. 27-79; S. Robles Rivera, «El misterio trinitario en la teología feminista. Reflexiones para una antropología inclusiva», Palabra y Razón 13 (2018), p. 68; J. Verschueren, 2013, op. cit., pp. 82-105. 
La práctica literaria, consistente en el intercambio comunicativo de un discurso artístico en una lengua, está igualmente situada espaciotemporalmente, es decir, se encuentra dotada de una diversidad de significaciones acordes con la época y el lugar en que sucede. El signo lingüístico que constituye el código esencial para dar forma a dicha práctica solo cobra sentido cuando los interlocutores que lo construyen-perciben lo dotan de un significado arraigado espacio-temporalmente ${ }^{8}$. La relación intersubjetiva de esta práctica tiene su razón de ser en una interacción en la que el lector real construye el significado desde su propio yo antropológico (abarcando sus características socioculturales de edad, sexo, clase, sociedad, lengua...), fusionándose con la interrelación entre el lector modelo que tenía en mente el autor al producir el texto, el autor modelo creado por el lector empírico y el autor empírico que una vez existióp. La comprensión empírica del mensaje, tal y como la entiende el escritor ${ }^{10}$, no va a suceder si el lector no ha sido mínimamente acostumbrado a interpretar los mensajes del escritor como este espera que lo haga ${ }^{11}$.

Si a estos dos tipos de práctica sociocultural (la que genera conocimiento y la que genera discursos artísticos en un idioma) se les aplica una perspectiva de género, se obtienen entonces los dos niveles de análisis en los que se mueve este trabajo: el del hombre investigador o historiador de la literatura que construye conocimiento (práctica científica) sobre otros hombres investigados o escritores (práctica literaria) y el de la vetada mujer investigadora o historiadora de la literatura (práctica científica) que a duras penas aspira a ser investigada o escritora (práctica literaria).

En otras palabras: las modalidades de opresión/represión efectuadas sobre las mujeres a lo largo de la historia ${ }^{12}$ traen como consecuencia que

8 Cf. V. Blanco Gallardo, op. cit., 2010, pp. 102-105; T. A. Van Dijk, Sociedad y discurso, Barcelona: Gedisa, 2011; D. R. Olson, op. cit.; S. Robles Rivera, 2018, op. cit., p. 68.

9 Cf. U. Eco, Lector in fabula. La cooperación interpretativa en el texto narrativo, Barcelona: Lumen, 1993, pp. 92-95.

10 Cf. M. Nystrand, M. Himley y A. Doyle, The structure of written communication. Studies in Reciprocity between Writers and Readers, Orlando: FL Academic Press, 1986, pp. 26-27; U. Eco, 1993, op. cit., pp. 73-95; J. Verschueren, 2013, op. cit., pp. 82-105.

11 Cf. L. Bohannan, «Shakespeare in the Bush. An American anthropologist set out to study the Tiv of West Africa and was taught the true meaning of Hamlet", Natural History 75 (1966), 28-33; V. Blanco Gallardo, 2010, op. cit.; D. R. Olson, 2013, op. cit. 12 Cf. T. López Pardina, «El cuerpo de las mujeres como locus de opresión/ represión», Investigaciones Feministas 6 (2015), pp. 60-68. 
el hombre pueda acceder con mayor o menor libertad según la época y el lugar tanto a la práctica científica (que implica determinar qué se investiga y qué no para crear conocimiento) como a la práctica literaria (que implica decidir quién puede escribir literatura y quién no), mientras que la mujer es automáticamente excluida de la primera (por opresión), altamente controlada en la segunda (por represión) y completamente ignorada en la interrelación entre la segunda y la primera, pues no se la considera un testigo fiable que con su práctica literaria (o cualquier otra práctica) pueda alterar lo más mínimo la práctica científica ${ }^{13}$.

El objetivo del presente artículo supone aplicar críticamente una perspectiva de género a la interrelación que se produce entre ambos tipos de práctica sociocultural (la científica y la literaria) para demostrar los problemas epistemológicos que entraña la selección del canon literario ${ }^{14}$ a partir de un texto concreto. Para ello, se toma un soneto de María de San José Salazar (1548-1603) como punto de partida, porque resulta altamente sorprendente que nadie, por lo que sabemos, lo haya asociado con un conocido poema de Lope de Vega (1562-1635), pese a los parecidos formales y conceptuales que comparten. No pretendemos, pues, determinar la verdadera relación entre ambos textos, tarea que merecería un estudio histórico-filológico aparte, sino cuestionar el olvido en el que ha caído el texto de María de San José Salazar (como los de muchas otras mujeres) por no compartir una ideología de género acorde con la época sociohistórica en que se compuso, ni desde la perspectiva extradiscursiva de la práctica científica (pues los estudiosos de la historia de la literatura son varones y ella no), ni desde la perspectiva intradiscursiva de la práctica literaria (dado que los conceptos internos al propio texto rechazan los fundamentos teóricos del patriarcado en que se inscribe).

13 Cf. A. Tanesini, 1999, op. cit., pp. 110-111. Esta misma idea se expone detalladamente en J. Lewandowska, Escritoras monjas: autoridad y autoría en la escritura conventual femenina de los Siglos de Oro, Madrid/Frankfurt: Iberoamericana/Vervuert, 2019, cap. 2 y en P. Fernández Martín, "Conocimiento, poder y religión», Investigaciones Feministas 11 (1) (2020), 155-165.

14 Cf. M. ${ }^{a}$ C. Servén Díez, "Canon literario, educación y escritura femenina», Ocnos: revista de estudios sobre lectura 4 (2008), p. 8; A. Steffanell, «Sor Francisca Josefa de Castillo (1671-1742): una "rara avis" en el canon de la literatura colombiana fundacional", Cuadernos de Literatura 14/28 (2010), p. 103; J. Lewandowska, 2013, op. cit. 
El presente trabajo, pues, comienza manifestando varias hipótesis que pueden dar sentido a la relación entre ambos poemas, sin entrar, como se ha dicho, en un estudio histórico-filológico, pero con el fin último de plantear el problema $(\$ 2)$. A continuación, exponemos, siguiendo la esencia de la epistemología feminista clásica ${ }^{15}$, los motivos extradiscursivos (práctica científica) que explican la indiferencia en que han caído los textos femeninos a lo largo de la historia y, en concreto, el que nos ocupa (\$3). Haciendo nuestro el concepto de práctica sociocultural de Ángel Díaz de $\operatorname{Rada}^{16}$, mostramos seguidamente los motivos intradiscursivos (práctica literaria) que contribuyen a la invisibilización del mencionado poema femenino, pues las propias palabras del texto de María, por ser inclusivo en el sentido que se explicará en su momento, se ajustan menos a una cosmovisión patriarcal que las palabras que componen el texto lopesco $(\$ 4)$. Unas síntesis finales, naturalmente, cierran el presente texto $(\$ 5)$.

\section{Planteamiento del Problema: una intertextualidad FEMENINA INVISIBILIZADA.}

Los textos que nos sirven como punto de partida para nuestra crítica a la epistemología en el doble sentido mencionado anteriormente (como práctica científica y como práctica literaria) pertenecen a María de San José Salazar (1548-1603) y a Félix Lope de Vega Carpio (1562-1635). Si se les aplica un esquema de análisis de los respectivos contextos de producción en que se crean ${ }^{17}$, se comprueba fácilmente que en dos de ellos hay una diferencia altamente significativa en el trato de sus respectivos textos. Consideremos, pues, dicho esquema en tres niveles de análisis ${ }^{18}$ : a) el macrocontexto sociohistórico, conformado por aquellos factores sociológicos que pueden ser relevantes para comprender al autor, reducibles aquí, por cuestiones metodológicas, al grupo social o profesión, género, edad, sociedad de origen e identidad lingüística; b) el entorno que rodea a

\footnotetext{
15 Cf. A. Tanesini, 1999, op. cit.

16 Cf. Á. Díaz de Rada, 2010, op. cit. Ya se ha dicho que nosotros no distinguimos entre «social» y «cultural», siguiendo a Kuper, 2001, op. cit. y a Ramírez Goicochea, 2009, op. cit.

17 Cf. M. Nystrand et alii, 1986, op. cit.

18 Cf. P. Fernández Martín, «La deixis personal en algunas cartas de Rosalía de Castro y Emilia Pardo Bazán desde la gramática funcional del discurso", Madrygal. Revista De Estudios Gallegos 22 (2019), 135-159.
} 
cada situación comunicativa plasmada en los diversos productos textuales estudiados, y limitado aquí analíticamente a los factores característicos de la clásica lingüística del texto ${ }^{19}$ : intencionalidad, aceptabilidad, informatividad, situacionalidad e intertextualidad ${ }^{20}$; y c) el microcontexto, que es el cotexto estrictamente lingüístico, en este trabajo incluido en el análisis intradiscursivo (cf. infra, $\$ 4$ ).

María de San José nace en 1548 en el seno de una familia bien posicionada, que le permite a los pocos años de edad servir a la aristócrata doña Luisa de la Cerda (emparentada con los Medinaceli y con los Mendoza) hasta 1562, que es cuando Teresa de Ávila la conoce y por la cual decide tomar el hábito en Malagón en 1570 y, al año siguiente, profesar en la orden del Carmelo Descalzo. En 1575 se instala en Sevilla por sugerencia de la fundadora para hacerse cargo del convento recién creado. Dos años después de la muerte de la abulense en 1582, va a Lisboa, donde vive entre felicidad y penuria hasta 1603, sumida en diversos enfrentamientos con algunos superiores por mantener el legado teresiano. En septiembre de dicho año 1603 es sacada del convento lisboeta y llevada, contra su voluntad, hasta Cuerva (Toledo), donde muere el 19 de octubre ${ }^{21}$.

Lope de Vega, figura de sobra conocida ${ }^{22}$, nace en Madrid en 1562 y muere en 1635 , rodeado de una fama de insaciable amante y dramaturgo de éxito. La principal diferencia, pues, desde una perspectiva metodológica,

19 R. Beaugrande y W. U. Dressler, Introducción a la lingüística del texto, Barcelona: Ariel, 1997.

20 Cf. M. Nystrand et alii, 1986, op. cit.; T. A. Van Dijk, Discourse and Context: A Sociocognitive Approach, Cambridge: CUP, 2008.

21 Cf. J. Vicente Rodríguez, María de San José (Salazar), Madrid: San Pablo, 2018; M. P. Manero Sorolla, "Diálogos de carmelitas: Libro de Recreaciones de María de San José», en A. Vilanova (comp.): Actas del X Congreso de la Asociación Internacional de Hispanistas: Barcelona 21-26 de agosto de 1989, Vol. 1, 1992, pp. 503-505; M. P. Manero Sorolla, «La Biblia en el Carmelo femenino: la obra de María de San José (Salazar)», en J. Whicker (ed.), Actas del XII Congreso de la Asociación Internacional de Hispanistas: 2126 de agosto de 1995, Birmingham, Vol. 3, 1998, p. 53; I. Morujão, "María de San José (Salazar) OCD, fundadora del primer Carmelo Descalzo femenino en Portugal», Revista de Espiritualidad 63 (2004), 177-211.

22 Cf. A. Alonso, «Lope de Vega y sus fuentes», Thesaurus: Boletin del Instituto Caro y Cuervo 48/2 (1952), 3-26; G. L. Guitarte, "La sensibilidad de Lope de Vega a la voz humana", Anuario de Letras: Lingüistica y filología 16 (1977), 165-195; F. B. Pedraza Jiménez, Lope de Vega. Pasiones, obra y fortuna del "monstruo de naturaleza», Madrid: EDAF, 2009. 
dentro del macrocontexto sociohistórico, es el género, pues ambos han nacido en el centro de Castilla (aunque él sea cortesano y ella no), lo que implica una similar identidad lingüística, pertenecen a la clase burguesa; comparten vocación religiosa, aunque sea de forma asíncrona, y tienen edades similares cuando escriben los poemas. Estos, por cierto, son como siguen:

Pobre el vestido, limpio, sin cuidado, un rostro afable, grave, alegre, honesto, un trato honroso, sincero y modesto.

A la verdad el corazón ligado, un valeroso pecho al bien atado sin que temor o amor le mude el puesto conforme a Dios, en todo al hombre opuesto,

por sí mismo temblando sosegado.

Buscar a Dios por solo ser Dios bueno; abrazar con el alma la pobreza; tener por libertad el ser mandada, el corazón vacío, de Dios lleno; conocer la soberbia en su bajeza; esto es ser carmelita reformada. María de San José (Salazar) Lisboa, 1589

\section{Varios efectos del amor}

Desmayarse, atreverse, estar furioso, áspero, tierno, liberal, esquivo, alentado, mortal, difunto, vivo, leal, traidor, cobarde y animoso; no hallar fuera del bien centro y reposo, mostrarse alegre, triste, humilde, altivo, enojado, valiente, fugitivo, satisfecho, ofendido, receloso; huir el rostro al claro desengaño, beber veneno por licor suave, olvidar el provecho, amar el daño; creer que un cielo en un infierno cabe, dar la vida y el alma a un desengaño; esto es amor; quien lo probó, lo sabe.

Félix Lope de Vega y Carpio Madrid, 1602

En lo que se ha considerado el entorno que rodea a cada situación comunicativa plasmada en estos poemas sí cabe encontrar mayores diferencias, que se irán desgranando en los siguientes apartados. A modo de síntesis, no obstante, conviene señalar que la intencionalidad de cada uno de los autores varía, al igual que lo hace el grado de aceptabilidad entre los lectores de la época (como muestra, naturalmente, el valor epistemológico que ha alcanzado el texto lopesco frente a la invisibilización que ha sufrido el de María) y el de relevancia informativa de los lectores de épocas posteriores. Esta relevancia no puede entenderse sin la situacionalidad de toda la obra poética de una ${ }^{23}$ y otro (que evidentemente también ha sido estudiada de muy desigual manera) y, naturalmente, sin la intertextualidad totalmente

23 Cf. M. P. Manero Sorolla, «La poesía de María de san José (Salazar)», en Estudios sobre escritoras hispánicas en honor de Georgina Sabat-Rivers. Madrid: Castalia, 1992, pp. 187-222. 
inexistente en el caso del poema de la carmelita y abrumadoramente recuperada en el del madrileño.

Este rasgo, el de la intertextualidad, es precisamente el que más nos interesa, pues es el que da una visión real de la importancia de un texto a lo largo de la historia, no solo porque haya podido influir de facto en otro texto que acaba siendo considerado magistral, sino porque, en ocasiones, ni siquiera parece dársele la opción de haber funcionado como posible fuente $^{24}$. Así, aunque ya se ha indicado que no se pretende establecer un estudio histórico-filológico de la intertextualidad susceptible de existir entre estos dos textos, sí deseamos dejar esbozadas las dos posibles hipótesis que barajamos: bien existe una fuente común a ambos; bien uno ha sido influido por el otro.

La primera hipótesis supone la existencia de una fuente común a los dos textos, de la cual hubieran bebido ambos autores. Las probabilidades son amplias, pues ambos contaban con una amplia educación, estaban en constante contacto con las distintas corrientes culturales del momento y tuvieron la oportunidad de explotar literariamente todas sus lecturas de juventud: ella, en casa de doña Luisa de la Cerda, habría recibido una refinada educación que la haría extraordinariamente culta ${ }^{25}$; él, anecdóticamente, parecía estar decidido a hacer, a su modo, un cancionero petrarquista cuando publica las Rimas en 1602. Según esta hipótesis, cada uno habría escrito su respectivo texto sin conocer el del otro, pero teniendo como posible modelo común algún otro poema similar, como, por ejemplo, el soneto CXXXIV de Petrarca («Pace non trovo, et non ò da far guerra»), adaptado al español como el soneto X (de las traducciones) del poeta renacentista Francisco de la Torre ( No hallo paz ni estoy para dar guerra») ${ }^{26}$; o el soneto $\mathrm{V}$ de Luís de Camóes («Amor é um fogo que arde sem se ver»), traducido por el Marqués de Lozoya a principios del siglo

24 Cf. A. Alonso, 1952, op. cit.

25 Dominaba el latín y conocía el francés; seguramente había accedido a los clásicos, pues desde muy joven siente admiración por la literatura. Recuérdese que la misma santa Teresa la llamaba «monja letrera», como bien se explica en M. P. Manero Sorolla, 1998, op. cit., p. 53. Su poesía es, además, frecuentemente escrita en versos cultos, de arte mayor, como el soneto que analizamos a continuación, lo que es un claro indicador de la erudición que irradiaba Salazar, como explica I. Morujão, 2004, op. cit., pp. 204-206.

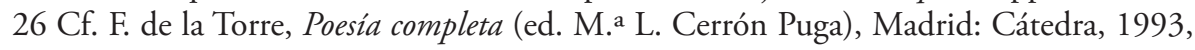
p. 305 . 
$\mathrm{XX}$ («Fuego es amor que oculto suele arder») ${ }^{27}$. Esta última influencia, sin embargo, es más difícil de justificar, si nos atenemos estrictamente a las fechas de la publicación del soneto portugués, que no apareció hasta 1595 junto con otros muchos poemas del autor.

La segunda hipótesis, a su vez, es doble, pues supone asumir la influencia de un texto sobre el otro. Una posibilidad sería, entonces, que esta influencia fluyera desde Lope de Vega hacia Salazar, de tal forma que ella hubiera accedido al texto de él en algún momento de su vida, le hubiera parecido interesante contrahacerlo al divino modo y de ahí hubiera resultado una guía deontológica sobre el buen ser carmelita reformada. En este caso, habría que asumir que el texto de Félix fuera anterior al de María y que, además, ella lo hubiera conocido sin que estuviera publicado. Para que esto ocurriera (posible, pero improbable), habría que demostrar que su texto formaría parte del supuesto grupo de poemas redactados en los años 80 del siglo XVI aunque publicados en 1602, por un lado; y justificar cómo le habría llegado ese texto a ella antes de 1589, que es cuando la mujer compone el suyo, esto es, más de diez años antes de la publicación de La hermosura de Angélica de dicho año de 1602 (que es la obra que lo incluye), por otro lado.

La otra posibilidad, por el contrario, sería que él hubiera tenido acceso de alguna forma al soneto de la religiosa y lo hubiera utilizado como posible inspiración para definir el amor puramente humano que sentía en ese momento de su vida. En este supuesto, habría que explicar cómo un poema escrito por una carmelita para un círculo privado (sus monjas) sale del convento lisboeta y, después, llega a la corte castellana ${ }^{28}$. Podría incluso aceptarse que ella hubiera enviado el poema a algún contacto en Madrid (donde habitaba el dramaturgo por esas fechas), inserto en alguna carta, pero seguiría siendo un misterio la manera en que Lope hubiera accedido al mundo eclesiástico carmelitano a finales del siglo XVI para leerlo.

Se confirme la hipótesis que se confirme (ya se ha dicho que esto no se va a tratar aquí), lo que parece incuestionable es que el olvido del texto de la carmelita descalza no es más que un recordatorio crítico de la visión

27 Cf. F. de Figueiredo, Camoens. Vol. III (trad. Marqués de Lozoya), Madrid: Voluntad, 1928, pp. 68-69.

28 Resulta bastante extraño que los poemas escritos por carmelitas salgan de esos círculos carmelitanos, como bien explica M. P. Manero Sorolla, 1992, op. cit., p. 505. 
esencialmente masculina de los estudios históricos de la literatura realizados hasta épocas recientes ${ }^{29}$. Si ambos han bebido de una fuente común, sin acceso al texto del otro, ambos se merecen entonces la misma posición en el canon de la historia de la literatura, algo que, como parece evidente, no ha ocurrido. Si el texto de él es anterior al de ella y ella, por tanto, lo aplica a la confección de su propio poema, necesita cuando menos el mismo reconocimiento que tienen otros poetas como Quevedo («Es hielo abrasador, es fuego helado...» y "Osar, temer, amar y aborrecerse...») o Villamediana («Determinarse y luego arrepentirse...»), que siguen el modelo poético lopesco en algunos de sus textos y así aparecen $\operatorname{citados}^{30}$. Si el texto de la mujer sirve de inspiración al soneto de Lope de Vega, resulta entonces inquietante que, hasta donde se sabe, nadie nunca lo haya resaltado, a) bien porque los estudiosos de la obra de la monja no coincidan con los estudiosos de la obra del dramaturgo y, por tanto, carezcan de mutuos datos como para interrelacionarlos; b) bien porque los críticos literarios, en general, se han sentido siempre lo suficientemente obnubilados por la importancia del Fénix de los Ingenios como para dejar de lado la mera posibilidad de que a él le influyeran otras fuentes socialmente consideradas más humildes; c) bien porque, finalmente, se haya siempre apartado (de la visión patriarcal del estudio histórico literario) la probabilidad de que una mujer (religiosa) sirviera de (posible) ejemplo poético a semejante Monstruo de la Naturaleza.

\section{Motivos EXTRAdISCURSIVOS: LA PRÁCTICA CIENTÍFICA DE UNA INTERTEXTUALIDAD INVISIBILIZADA.}

En este apartado se va a efectuar el análisis de los textos indicados desde una perspectiva extradiscursiva, que hace equivaler las tres características que debería cumplir toda epistemología, de acuerdo con Tanesini ${ }^{31}$, con tres de los motivos por los que entendemos que ha sido invisibilizado el poema de María de San José Salazar (y los de tantas otras muchas mujeres): frente a la visión oficial que entiende la práctica científica como individual, toda

29 Cf. C. Servén Díez, 2008, op. cit.; A. Stefannell, 2010, op. cit.; J. Lewandowska, 2013, op. cit.

30 Cf. M. Trapero, «Un tema y dos estilos», Boletín Millares Carlo 3 (1981), 189-204; así consta igualmente en la edición manejada de García-Posada, 1992, p.155.

31 Cf. A. Tanesini, 1999, op. cit., pp. 3-37. 
práctica científica es una práctica sociocultural, esto es, conlleva una serie de comportamientos anclados cronotópicamente $(\$ 3.1)$; a diferencia de la epistemología tradicional, que se considera neutral, todo conocimiento, en tanto construido socioculturalmente, no puede carecer de juicios de valor (\$3.2); en contraste con la ciencia tradicional que es asumida como teórica, ciertas prácticas femeninas, tanto por ser femeninas como por ser prácticas, no se pueden considerar «conocimiento de segunda» (\$3.3).

\section{III.1. LA PRÁCTICA CIENTÍFICA COMO PRÁCTICA SOCIOCULTURAL.}

La historia de la literatura, entendida aquí como una práctica científica cuyo fin último consiste en estudiar diacrónicamente los discursos artísticos que son el producto de un intercambio comunicativo en una lengua concreta durante cierta época en un lugar determinado, no es una excepción a la historia general del conocimiento científico que ha ejercido una constante selección en lo que compone su objeto de estudio ${ }^{32}$. La elección de los textos que han formado parte de su canon (hasta época reciente) se ha basado más en los factores socioculturales que caracterizan a sus productores (clase social, género, lengua...) que en los textos per se, lo que ha dado como consecuencia excluir del estudio aquellos textos escritos por quienes no comparten dichos factores socioculturales, entre otros, las mujeres, convertidas así en "protagonistas ausentes» de la historia ${ }^{33}$.

A modo de prueba, cabe defender el frecuente error en el que se cae cuando se señala que los textos (literarios) están descontextualizados ${ }^{34} \mathrm{o}$ que, en general, cualquier texto escrito es objetivo ${ }^{35}$ : si realmente estos textos, desde la práctica literaria, estuvieran descontextualizados, porque sus autores fueran, por ejemplo, seres etéreos a-tópicos y a-crónicos, entonces habrían sido estudiados, desde la práctica científica, con una objetividad ideal, como puras categorías ontológicas (a modo de ideas

32 Cf. A. Tanesini, 1999, op. cit.; J. A. Díez y C. U. Moulines, 2008, op. cit; C. Servén Díez, 2008, op. cit., pp. 9-10.

33 Cf. C. Servén Díez, 2008, op. cit., pp. 8-10; A. Steffanell, 2010, op. cit., p. 103; J. Lewandowska, 2013, op. cit., pp. 14-16; 2020, op. cit.

34 Cf. H. M. Velasco, Hablary pensar, tareas culturales. Temas de Antropología Lingüistica y Antropología Cognitiva, Madrid: UNED, 2003, pp. 235-238; J. P. Denny, «El pensamiento racional en la cultura oral y la descontextualización escrita», en D. R. Olson y N. Torrance, Cultura escrita y oralidad, Barcelona: Gedisa, 2013, pp. 95-126.

35 Cf. D.R. Olson, 2013, op. cit. 
platónicas, por así decirlo), y como consecuencia se habría reconocido el valor objetivo de su interior textual, sin que los rasgos de sus autores pudieran ser considerados relevantes para ser analizados.

La realidad, no obstante, dista mucho de ser ideal, aunque se siga insistiendo en ello desde la práctica científica. En esta, al dar constantemente por hecho que el texto (entendido como producto de la práctica literaria) está descontextualizado, se implica la naturalización de una práctica que es sin duda sociocultural, de semejante manera a como opera la metafísica platónica, extraordinariamente ideal, pero con la necesidad legitimadora (real) del poder establecido ${ }^{36}$. La práctica científica, entonces, obvia la esencia misma de la práctica literaria, ya que no se puede esgrimir la brecha temporal entre el contexto de producción (redacción) y el contexto de situación (interpretación) como motivo para defender que la escritura es un proceso descontextualizado ${ }^{37}$.

En otras palabras, si el texto de Lope de Vega (práctica literaria) ha implicado, primero, una extraordinaria aceptabilidad y, segundo, una inesperada informatividad, que han hecho correr ríos de tinta durante siglos de historia de la literatura ${ }^{38}$, y el de María de San José no se ha trabajado lo suficiente, no ha sido porque se haya estudiado como un producto literario descontextualizado (práctica científica), sino porque ha sido producido por un hombre de la áurea corte castellana durante una época en la que la ideología de género (junto con otras muchas ideologías reinantes, naturalmente) primaba los textos masculinos sobre los femeninos (cf. infra, \$3.2). Igualmente, el estudioso de la historia de la literatura (práctica científica) que ha dedicado su vida a investigar textos literarios como el mencionado (práctica literaria) no ha ejercido ninguna suprema objetividad (incluso la libertad de elección de su objeto de estudio es dudosamente objetiva) al seleccionar los textos de análisis de entre todos los posibles, tan solo se ha dejado llevar por su yo (plenamente sociocultural) y por el grado de identificación que no puede evitar sentir

36 Cf. T. Oñate y Zubía, El nacimiento de la Filosofía en Grecia. Viaje al inicio de Occidente, Madrid: Dykinson, 2003, pp. 333-336; C. Servén Díaz, 2008, op. cit.; J. Lewandowska, 2013, op. cit.; A. Steffanell, A., 2010, op. cit.

37 Cf. M. Nystrand et alii, 1986, op. cit.; J, Verschueren, 2013, op. cit.

38 Cf. A. Alonso, 1952, op. cit.; G. L. Guitarte, 1977, op. cit.; F. B. Pedraza Jiménez, 2009, op. cit. 
con el autor ${ }^{39}$, con todo lo que ello implique de intereses geopolíticos más o menos encubiertos ${ }^{40}$.

A esta esencia de la práctica científica como práctica sociocultural cabe ańadir una reflexión sobre el valor de lo estético, peculiaridad reinante en la práctica literaria que es ajena a otras prácticas socioculturales, pero no a la práctica científica encargada de estudiarla. En efecto, además de ser un intercambio comunicativo de un discurso en una lengua, la práctica literaria se caracteriza por una función estética que alimenta el prestigio social de la clase dominante, al fomentar el placer artístico de los lectores/ oyentes cuando entran en contacto con é ${ }^{41} \mathrm{y}$ al permitir así la entrada de esa obra en el canon ${ }^{42}$, como de hecho parece haber ocurrido también en la historia de la filosofía, que ha puesto siempre el foco en el arte oficial, prestigioso, por ser practicado por los poderosos dentro de la sociedad en cuestión, pero coexistente durante siglos con el arte popular, menos valorado por haber sido llevado a la práctica por personas no autorizadas socialmente para ello ${ }^{43}$.

Entre el colectivo de «personas no autorizadas» se encuentran, naturalmente, numerosas mujeres que, por cuestiones de ideología de género (cf. infra, \$3.2), no han sido incorporadas al estándar artístico de la sociedad en que se encontraban ${ }^{44}$. Como se ha indicado, esta exclusión de la práctica literaria, que a pesar de todo han ejercido a su manera ${ }^{45}$, ha sido la perfecta excusa para ser excluidas también de la práctica científica, en el doble nivel de investigadoras (pues no podían ser historiadoras de la literatura) y de investigadas (pues sus textos no se consideraban relevantes como objetos de estudio).

Cabe, por tanto, defender que, si se asume que la lengua literaria no surge de la nada sino a partir de la lengua común ${ }^{46}$, no hay nada inherente

39 Cf. U. Eco, 1993, op. cit.

40 Cf. A. Steffanell, 2010, op. cit.

41 Cf. J. Mukařovský, Escritos de estética y semiótica del arte, Barcelona: Gustavo Gili, 1977.

42 Cf. A. Steffanell, 2010, op. cit., p. 103.

43 Cf. T. Oñate y Zubía, 2003, op. cit.; J. Dewey, El arte como experiencia, Barcelona: Paidós, 2008, p. 211.

44 Cf. C. Servén Díez, 2008, op. cit., p. 11; A. Steffanell, 2010, op. cit., p.103.

45 Cf. J. Lewandowska, 2013, op. cit., p. 13; 2019, op. cit., cap. 2; S. Robles Rivera, 2018, op. cit., p. 68.

46 Cf. J. Mukařovský, 1977, op. cit. 
al propio idioma (que en nuestro caso es plenamente compartido por María de Salazar y Lope de Vega) que garantice la belleza de ambos poemas por sí mismos, pues esta se encuentra, como decimos, en el contexto sociocultural en que se produce la lectura, el cual a su vez fomenta las expectativas de belleza estética que ha de desarrollar el lector.

\section{III.2. El CONOCIMIENTO COMO JUICIO DE VALOR.}

A lo largo de la historia, los escritos de las mujeres no han sido estudiados en profundidad por las cuestiones ideológicas que subyacen a la desigualdad de los géneros en prácticamente todas las sociedades. Posibles excepciones como los textos de Catalina de Siena, Teresa de Ávila o Francisca Josefa de Castillo ${ }^{47}$, generalmente tildados (no sin cierto atisbo de desprecio) de «literatura espiritual y devocional ${ }^{48}$, en realidad no constituyen excepción alguna, pues su categorización discursiva como literatura mística veta la posibilidad de que puedan pertenecer textualmente a disciplinas de mayor prestigio sociocultural, como la filosofía o la teología ${ }^{49}$. A la larga, esta categorización excluyente oculta la lucha de poder que se esconde tras la ideología de género que forma parte de los valores socioculturales que, circularmente, determinan qué práctica discursiva tiene prestigio y cuál carece de él ${ }^{50}$.

En efecto, la ideología de género, en tanto ideología, es el conjunto subyacente de pautas de significado, marcos de interpretación, visiones del mundo o formas de pensamiento y explicación del día a día que, integradas sociocognitivamente, implican relacionas de poder incuestionadas que, aplicadas a la categoría sociocultural de género, se acaban asumiendo como

47 Cf. A. Steffanell, 2010, op. cit.; y P. Fernández Martín, «Discurso feminista colombiano preilustrado: la imagen femenina en la Vida de Sor Francisca de la Concepción», Revista Cultura \& Religión XV (1) (2021), pp. 109-146.

48 Cf. L. Ramón, Queremos el pan y las rosas. Emancipación de las mujeres y cristianismo. Madrid: HOAC, 2010, p. 157.

49 Cf. T. Forcades i Vila, La teología feminista en la historia, Barcelona: Fragmenta, 2011, pp. 23-40; J. Lewandowska, 2013, op. cit., p. 25; J. J. Llamedo González, Teología de Teresa de Jesús. Doctora de la Iglesia. Una visión sistematizada, Madrid: San Pablo, 2018; P. Fernández Martín, 2020, op. cit.

50 Cf. A. Tanesini, 1999, op. cit.; C. Servén Díez, 2008, op. cit., p. 11; A. Steffanell, 2010, op. cit., p. 103. 
normales $^{51}$. La categoría de género, empleada entonces como categoría analítica, marca «la interrelación entre la distinción sexual genital, las construcciones sociales y la asignación de modos de autoconcebirse, de ser y de estar en el mundo ${ }^{52}$. La tradición, apoyada en la ideología de género dominante, ha indicado que sea la masculinidad el modelo para establecer pautas de comportamiento guiadas por concepciones universalizantes de la realidad particular que, naturalmente, afectan también a la práctica científica $^{53}$. Si, como se ha indicado anteriormente (cf. supra, \$3.1), el lector encargado de seleccionar los textos que forman parte del canon literario es hombre, porque, por ejemplo, a la mujer se le veta el derecho a

51 Entendemos por «normal» lo que se acaba convirtiendo en norma, a modo de hábitus bourdienano, estructura estructurante hecha estructura estructurada. Estamos siguiendo, en cualquier caso, el concepto de ideología establecido por J. Verschueren, op. cit., 2013, pp. 7-10, el cual solo puede concebirse como «bueno» $\mathrm{o}$ "malo» a posteriori, nunca desde una perspectiva que entienda realmente el contexto sociocultural del momento en que se encuentran los textos analizados. De ahí que lo importante, como dice el mismo J. Verschueren, 2013, op. cit., p. 197, es reconocer la propia ideología, pues los juicios de valor sobre ella vendrán después.

52 Cf. S. Robles Rivera, 2018, op. cit., p. 66.

53 Se entiende, entonces, que todo investigador está impregnado de la ideología de la sociocultura en que le ha tocado vivir, lo cual no debería ser un problema siempre que lo reconozca y, en la medida de lo posible, no intente esconderlo. La dificultad metodológica se encuentra en no asumir este problema, e intentar objetivar una investigación que es, por esencia, subjetiva, y esconder, bajo conceptos como «lo natural» o «lo normal» (tomado, entonces, por inmodificable), una decisión convencional que es puramente social (y, por tanto, evitable). El hecho de que el lector mantenga una ideología, en sí mismo, no es un problema para la investigación, en palabras de J. Verschueren, 2013, op. cit., p. 197, «as long as researchers know what they are doing when bringing in their own point of view, and as long as they do not try to hide their own involvement». Cabe asumir, entonces, que la presente investigación defiende la ideología feminista que sigue la línea de la obra de María de San José Salazar, a su vez en concordancia con el pensamiento de otras mujeres como Christine de Pizan, Isabel de Villena y, por supuesto, santa Teresa de Jesús, pues no se desea caer en el error de excluir del canon de la teoría feminista (como se ha hecho en el literario) a las filósofas pre-ilustradas que, en sus respectivos contextos socioculturales, pueden perfectamente serlo, como defienden, entre otras, T. Forcades i Vila, 2011, op. cit.; N. Bueno-Gómez, «Self-management and Narrativity in Teresa of Avila's work», Life Writing 15:3 (2018), 305-320; N. Bueno-Gómez, "I Desire to Suffer, Lord, because Thou didst Suffer": Teresa of Avila on Suffering» en Hypatia. A Journal of Feminist Philosophy 34:4 (2019), 755-776; y P. Fernández Martín, 2021, op. cit. 
la educación (práctica científica) ${ }^{54}$, su capacidad de elección de los textos que considera relevantes (práctica literaria) se convertirá en un juicio de valor de carácter plenamente subjetivo que ligará de forma directa a todo su yo, incluido aquello de lo que ni siquiera sea consciente, como es la ideología de género que subyace a sus propias elecciones.

La diferencia, entonces, entre los textos literarios excluidos del canon y los textos literarios incluidos en él no se encuentra ni en el lenguaje, ni en el tipo de texto, ni en la conciencia que del lector ha de tener necesariamente el escritor, sino en la situacionalidad en la que tiene lugar el texto y que se puede hacer aferrable en las dos atribuciones que surgen desde el preciso momento de su producción ${ }^{55}$ : el ansia de superación espaciotemporal del autor a través de la creación de la conciencia del yo (práctica literaria; cf. infra, \$4) y su empatía con un lector reconstruido por él mismo que algún día sepa de su existencia a través de los versos de su poema (práctica científica).

Es, sin embargo, en el lector real donde se encuentra el problema, ya que él es el responsable inicial de lo que se acaba incluyendo en lo que con el tiempo será la historia de la literatura. Este lector real está anclado, como se ha dicho, a un espacio-tiempo concreto (cf. supra, \$3.1), en el que prima una ideología específica que es la que determina, al final, qué es válido y qué no es válido para ser investigado ${ }^{56}$ : "Toda valoración de un texto literario es, en realidad, un juicio sobre lo bien que el texto en cuestión satisface las necesidades cambiantes de los individuos y las sociedades ${ }^{57}$.

$\mathrm{Al}$ aplicar esta idea de juicio de valor a la selección de nuestros sonetos, conviene recordar las dos tendencias temáticas en las que tradicionalmente se ha dividido la poesía renacentista, esto es, el amor y la religión ${ }^{58}$. Dado que parece que el texto de Lope se ajusta a la perfección al concepto de amor cortés (que, a su vez, ha contribuido a crear, pues desde la perspectiva

54 Cf. L. Nuño Gómez, El derecho a la educación. Estrategias patriarcales contra la genealogí femenina, Granada: Comares, 2020.

55 Cf. U. Eco, 1993, op. cit.

56 Cf. A. Steffanell, 2010, op. cit., pp. 105-109.

57 Cf. C. Servén Díez, 2008, op. cit., p. 8.

58 Cf. M. Darbord, "Ascéticos y místicos», en J. Canavaggio (dir.), Historia de la Literatura Española. Tomo II. El siglo XVI, Barcelona: Ariel, 1994, pp. 149-178; A. Labertit, «El nuevo esplendor de la poesía» en J. Canavaggio (dir.), Historia de la Literatura Española. Tomo II. El siglo XVI, Barcelona: Ariel, 1994, pp. 179-204. 
de género tiene autoridad para ello), resulta sorprendente la exclusión de un poema como el de María de San José (insistimos: entre otros muchos textos femeninos), en el que se explica con extraordinaria precisión en qué consiste su práctica religiosa (cf. infra, \$3.3), que parece ser el necesario principio de la experiencia mística plasmada en lo que se considera una poesía renacentista religiosa aceptable para el canon ${ }^{59}$. Así, resulta asombroso, por un lado, que el género discursivo de la poesía religiosa renacentista se haya reducido a incorporar solamente los textos de santa Teresa de Jesús, fray Luis de León y san Juan de la $\mathrm{Cruz}^{60}$, en lo que sigue siendo una mayoría de hombres; y, por otro lado, que parece que se haya exigido a las escritoras estar a la altura de la abulense para poder pertenecer al canon ${ }^{61}$, no solo en términos de práctica literaria (que sería lo que se les exigiría a los hombres en una situación similar) sino también en cuanto a modélica ejemplaridad del estilo de vida.

En otras palabras, mientras que todos los escritores que forman parte del canon literario no tienen por qué llevar una vida acorde con lo que definen sus textos (ni siquiera tienen por qué llevar una vida ejemplar ni modélica), a ellas se las excluye de él por su forma de plasmar el mundo en sus poemas en relación con la forma de vivirlo en su cuerpo ${ }^{62}$. Aplicando

59 Cf. S. Robles Rivera, 2018, op. cit., p. 74.

60 Cf. M. Darbord, 1994, op. cit.; J. I. Morera de Guijarro, «Márgenes de la mirada en la mística española» en M. González García y A. Sánchez (coords.), Renacimiento y Modernidad, Madrid: Tecnos, 2017, pp. 439-482.

61 Hay muchos ejemplos de lo que parece costarles a ciertos hombres incorporar textos femeninos al canon literario, en un afán por confirmar que no se emplea la misma vara de medir para ellos que para ellas. Así, en A. Steffanell, 2010, op. cit., pp. 110, 116, 122 puede consultarse lo que ocurrió con la obra de Francisca Josefa de Castillo que, en todo caso, puede leerse en clave feminista, como intenta hacer P. Fernández Martín, 2021, op. cit. En J. Lewandowska, 2013, op. cit., pp. 23-28 se explica qué pasó con Marcela de San Félix, la hija, precisamente, de Lope de Vega. Otros ejemplos surgen con muchas de las escritoras religiosas analizadas por Manuel Serrano y Sanz, «quien, como se sabe, reunió y estudió la obra parcial de más de trescientas escritoras españolas, aún calificando a las religiosas muy por debajo del excelso modelo teresiano", como explica M. P. Manero Sorolla, 1992, op. cit., p. 502. En esta misma obra (p. 505) se hace referencia al olvido que del Libro de Recreaciones de nuestra Salazar hace Jesús Gómez en su estudio sobre los diálogos en el Renacimiento español.

62 Por este tipo de motivos no se puede dejar de lado el aspecto biológico que conforma también la esencia biopsicosociocultural del ser humano que se defiende en Ramírez Goicoechea, 2009, op. cit., especialmente en un aspecto como el cuerpo que afecta tanto 
esta idea al idealizado amor cortés que se plasma en el soneto lopesco, cabe reflexionar sobre la relación entre la biografía real del poeta y lo que él escribe en su soneto, de la misma manera que tácitamente parece haberse hecho con el de María de San José, el cual ha sido excluido de la práctica científica porque stricto sensu no expresa una experiencia mística de acuerdo con los parámetros de la poesía religiosa renacentista de Luis de León y de Juan de Yepes que solo parece superar su maestra. Parece haberse dado, entonces, una confusión entre la voz lírica y la voz real de la autora que evita su inclusión en los estudios de historia de la literatura, algo que no sucede con los textos masculinos.

Siguiendo esta línea de pensamiento en la que se han de relacionar las circunstancias de producción textual con las que conllevan su interpretación, el poema de Lope se presta a ser una prueba más de las historias sentimentales que caracterizan al personaje. Publicado en las Rimas de 1602, se trata de un texto con el que pretende definir, a través de la experiencia, qué es exactamente el amor, adoptando una visión política en línea con el mencionado amor cortés, donde «la relación del enamorado y su Dama es, desde los orígenes trovadorescos de esta ideología, el resultado de la proyección del lazo feudal en el ámbito del amor» ${ }^{63}$, relación amorosa que implicaba, de acuerdo por ejemplo con Lacan, despojar por completo de corporeidad a la mujer, para evitar todo contacto carnal ${ }^{64}$.

Aparte de incidir en la oposición cuerpo-alma, tan perjudicial para la imagen femenina ${ }^{65}$, el amor cortés como marco axiológico de una época supone, en teoría, tres paradojas ${ }^{66}$ : la distancia en la proximidad, es decir,

a las mujeres, como explican L. Posada Kubissa, «Las mujeres son cuerpo: reflexiones feministas", Investigaciones Feministas 6, (2015), 108-121 y P. Fernández Martín, 2020, op. cit., entre muchas otras. Cf. infra, n. 86.

63 Cf. L. Funes, L. «Hacia Celestina: paradojas del ideal amoroso cortesano en los textos sentimentales castellanos», Letras 77 (2018), p. 98.

64 Cf. C. A. Andrade Mello, «Impasses do amor cortês», Reverso. Belo Horizonte 62 (2011), 28.

65 Así lo explica L. Posada Kubissa, op. cit. y, aplicado al ámbito discursivo de la mística teresiana, P. Fernández Martín, 2020, op. cit.

66 Se exponen simplificadamente las paradojas según las entiende L. Funes, 2018, op. cit., p. 101, que a su vez las extrae de la lectura realizada por Roger Chartier del texto de Norbert Elias sobre la sociedad cortesana: R. Chartier, «Formation sociale et économie psychique: la société de cour dans le procès de civilisation», 1985, prefacio de Norbert Elias, La Sociéte de cour, París: Flammarion-Champs, pp. I-LXXvII. 
a mayor proximidad espacial mayor distancia social; la identidad como apariencia, ya que el individuo es lo que el juicio efectuado por los demás determine que sea; y la superioridad en la sumisión, dado que se precisa reconocer su situación de inferioridad para preservar su lugar en la corte. Sin embargo, desde la ideología de género de la época áurea (heredada en mayor o menor grado del Medievo en el que nace el amor cortés), ninguna de estas paradojas realmente lo es. La primera implica entender que, por idealización compensatoria, a la mujer se la considera un objeto lejano, ajeno por completo al poeta, que sufre entonces por su ausencia y que solamente podrá conseguir por la fuerza, esto es, contra la voluntad de la propia mujer que, fuera del juego de la ficción poética, no deja de encontrarse en una posición socioculturalmente inferior. La segunda paradoja carece de sentido en el momento en que él, desde su hic-et-nunc del mundo, juzga lo que es la mujer, sin cuestionar que haya posibilidad de error, sin plantearse ni siquiera si es así como ella se juzga a sí misma $y$, tal vez lo que es peor, sin darle la voz que ella precisa para expresar la reciprocidad o el rechazo del amor, obligatoria si de verdad existe un deseo de que este no sea violento ${ }^{67}$. La dama que se idealiza deja de ser ella misma para pasar a convertirse en la dama del otro, transformándose en un objeto que alcanzar, mediante una estrategia de falsa sumisión poética, que es la tercera supuesta paradoja, pues solo alguien con cierta autoridad en el mundo real puede permitirse una rebaja ficticia durante toda una secular tradición literaria como la practicada por el amor cortés masculino ${ }^{68}$.

Frente a este valor atribuido a la experiencia amorosa que emana del texto lopesco, la intencionalidad de la religiosa es dejar por escrito, de forma artística, unas sencillas pautas de comportamiento para aquellas que quieran ser carmelitas descalzas. Recuérdese que su texto es redactado hacia 1589, en pleno enfrentamiento con el vicario general Nicolás Doria y en un delicado momento en que, seguramente, ella sintiera peligrar los fundamentos del espíritu reformista de la fundadora ${ }^{69}$. Por un lado, entonces, con el soneto pretendería simplemente describir el modo de

67 Cf. C. Servén Díez, 2008, op. cit., p. 9; J. Lewandowska, 2013, op. cit., pp. 21-22.

68 Cf. C. A. Andrade Mello, 2011, op. cit.

69 Resulta interesante destacar que, en la primera publicación de los poemas, realizada por Belchior de Santa Ana en su crónica de 1657, este poema se incluye "Para que se acordase la novicia de la obligación que tenía de procurar la gloriosa posesión de todas las virtudes», como refleja I. Morujāo, 2004, op. cit., p. 206, n. 78. 
ser que considera la esencia de su vida. Por otro lado, no puede dejar de relacionarse con la intencionalidad igualmente didáctica que atraviesa también su obra en prosa, como los Consejos que da a una priora (1590), el Tratado de los tres votos (1599) y, por supuesto, la Instrucción de novicias (1602), pues todas ellas intentan sugerir guías de conducta que sigan las normas propuestas por la fundadora ${ }^{70}$. Naturalmente, nada de esto tiene interés para el patriarcado desde el que se configura la práctica científica, pues la educación de las mujeres solo es "cosas de mujeres» ${ }^{71}$ que no alcanzan el supuesto prestigio universal que sí alcanza el amor carnal representado por la vida y obra de Lope de Vega ${ }^{72}$.

En síntesis, no sorprende, entonces, que quienes han estudiado en mayor profundidad la poesía de María de San José sean bien quienes se identifican con ella desde la perspectiva de género (es decir, mujeres), bien quienes, siendo hombres, se identifican con sus valores religiosos (es decir, carmelitas $)^{73}$. Parece, por tanto, indiscutible que mientras los historiadores

70 Cf. M. P. Manero Sorolla, 1991, op. cit., 1998, op. cit.; R. Pascual Elías, 2014, op. cit.; J. Vicente Rodríguez, 2018, op. cit.

71 Cf. C. Servén Díez, 2008, op. cit., pp. 9-12. Estas «cosas», sin embargo, ya habían calado en la misma María de San José, que sigue muy de cerca la creencia teresiana de que mejor se entienden las mujeres unas a otras, como indica M. P. Manero Sorolla, 1992, op. cit., p. 505, que remite a su vez a las Moradas, prólogo, 5. P. Fernández Martín, 2021, op. cit., ofrece también una peculiar visión de la imagen femenina en Francisca de la Concepción, que puede implicar cierto tipo de pre-feminismo. No obstante, para una revisión de la manera en que toda esta ideología afecta a la exclusión de la mujer de la educación, así como de las estrategias que el patriarcado ha efectuado para desprestigiarla, se recomienda la brillante monografía de L. Nuño Gómez, 2020, op. cit.

72 Cf. G. L. Guitarte, 1977, op. cit.; F. B. Pedraza Jiménez, 2009, op. cit.

73 Naturalmente, dentro de los hombres carmelitas la propia María de San José tuvo que lidiar con amigos y enemigos. Jerónimo Gracián de la Madre de Dios y San Juan de la Cruz estarían entre los primeros, mientras que Nicolás Doria, José de Jesús María (Quiroga), Jerónimo de San José (Ezquerra) y Francisco de Santa María (Pulgar) se encontrarían entre los segundos. Seguramente no les gustara la relativa independencia y autonomía que Salazar defendía, siguiendo las ideas teresianas, para el autogobierno de las mujeres. Cf. M. P. Manero Sorolla, 1998, op. cit., p. 57; 1992, op. cit., p. 501 e I. Morujão, 2004, op. cit., pp. 183-190. Para una revisión del papel de otros hombres no necesariamente de la orden, cf. C. Torres Sánchez, La clausura imposible. Conventualismo femenino y expansión contrarreformista, Madrid: Asociación Cultural Al-Mudayna, 2000, pp. 43-51. También merece la pena traer a colación la perplejidad que conllevó algún procedimiento formal de los carmelitas calzados por la composición poética de las descalzas, como bien se explica en I. Morujāo, 2004, op. cit., p. 203, n. 71. 
de la literatura han sido hombres ajenos a la orden religiosa en cuestión, el texto más estudiado ha sido aquel con el que se sentían más identificados, por mostrar valores socioculturales (entre otros, el amor cortés al modo renacentista) juzgados como cercanos a los mismos valores de los lectores y generalmente asumidos como universales ${ }^{74}$, mientras que el soneto de Salazar, como tantos otros, ha sido evaluado como irrelevante y, por ello, excluido de cualquier atisbo canónico.

\section{III.3. LA PRÁCTICA (RELIGIOSA) FEMENINA COMO SABER.}

El hecho de que el conocimiento femenino haya sido tradicionalmente práctico ha ocasionado su exclusión de la epistemología oficial centrada eminentemente en el conocimiento teórico. Si se asume, entonces, que todo conocimiento teórico es, al final, práctico, en tanto que la práctica implica la habilidad para responder, usar y producir cosas sin dejar por ello de dar forma a la persona en la configuración de sus emociones y creencias, el conocimiento producido por las mujeres debería ser epistemológicamente tan válido como el saber producido por los hombres ${ }^{75}$.

La realidad de la práctica científica, como se viene insistiendo en el trabajo, dista mucho de haber considerado por igual la práctica femenina y la práctica masculina. Dentro de la práctica femenina, cabe destacar el olvido general en el que ha caído la práctica religiosa, esencia de la práctica literaria de María de San José Salazar ${ }^{76}$, como objeto de conocimiento para la práctica científica de la filosofía-teología y de la historia de la literatura ${ }^{77}$, entre otras. Además, dicha práctica religiosa difícilmente puede comprenderse fuera de la situacionalidad marcada por la reivindicación

74 Cf. G. L. Guitarte, 1977, op. cit.; A. Tanesini, 1999, op. cit., p. 53; J. Lewandowska, 2013, op. cit., p. 15.

75 Cf. A. Tanesini, 1999, op. cit., pp. 12-15; A. Hollywood, «Practice, Belief and Feminist Philosophy of Religion", en P. S. Anderson y B. Clack (eds.), Feminist Philosophy of Religion. Critical Readings, Nueva York/Oxon: Routledge, 2004, p. 233.

76 Cf. M. P. Manero Sorolla, 1991, op. cit. Cf. también el $\$ 4$ del presente trabajo.

77 Cf. P. S. Anderson, "An epistemological-ethical approach», en P. S. Anderson y B. Clack (eds.), 2004, op. cit., p. 88; A. Hollywood, 2004, op. cit.; H. Walton, «Women writing the divine», en P. S. Anderson y B. Clack (eds.), 2004, op. cit.,130; C. Servén Díez, 2008, op. cit.; P. Fernández Martín, 2002, op. cit. 
protofeminista $^{78}$ de la obra fundadora de su maestra Teresa de Ávila y su experiencia mística, conceptualizada como la actitud humana ante la religión sin la cual esta no existiría ${ }^{79}$.

Analíticamente, pues, el fenómeno místico puede ser definido como un conjunto de "experiencias interiores, inmediatas, fruitivas, que tienen lugar en un nivel de conciencia que supera la que rige en la experiencia ordinaria y objetiva, de la unión [...] del fondo del sujeto con el todo, el universo, el absoluto, lo divino, Dios o el Espíritu» ${ }^{80}$. Al entenderlo, entonces, como un conjunto de experiencias puede analizarse como una práctica metafísicamente intersubjetiva constituida por cuatro factores: el mundo de lo sagrado, la presencia del Misterio, las formas de la experiencia mística y las mediaciones religiosas. Estas últimas ilustran la forma en que el mundo de lo visible asume el significado de lo invisible, de lo inefable, de lo santo ${ }^{81}$.

En efecto, las mediaciones entre las que se mueve la práctica religiosa de María de San José ofrecen una pauta de comportamiento relativamente clara a las personas que deciden seguirlas, plasmada a la perfección en el contenido de su soneto (cf. infra, \$4). En primer lugar, todo el poema es una evidente hierofanía que representa metafóricamente la figura de Jesús como modelo de vida que inspira el servicio religioso, algo "prohibido" por la teología oficial de muchos hombres, que consideran que la mujer debe parecerse a María, no a Cristo ${ }^{82}$. En segundo lugar, las mediaciones subjetivas comprenden un tiempo marcado por el calendario litúrgico, un espacio limitado por las paredes del convento, una serie de expresiones racionales (la virginidad de María, la resurrección de Cristo, la teología paulina...) que conforman el sistema de creencias en el cristianismo y, naturalmente, las expresiones activas en forma de culto (recuérdese la

\footnotetext{
78 Dado que en la actualidad la bibliografía que defiende el feminismo de Teresa de Ávila empieza a ser abundante, consideramos esencial mantener la línea de lo explicado en $\mathrm{N}$. Bueno-Gómez, 2018, op. cit., pp. 305-320 y 2019, op. cit., pp. 755-776.

79 Cf. J. Martín Velasco, Introducción a la fenomenología de la religión, Madrid: Trotta, 2006, pp. 161-194.

80 Cf. J. Martín Velasco, El fenómeno místico. Estudio comparado, Madrid: Trotta, 2009, p. 23.

81 Cf. J. Martín Velasco, 2006, op. cit., pp. 195-245.

82 Cf. A. Hollywood, 2004, op. cit., p. 235.
} 
oración como acto esencial de la actitud religiosa ${ }^{83}$ ) y servicio a Dios que, mediados por la sororidad conventual, dirigen toda la acción ética de la vida religiosa.

Como cristiano, Lope de Vega comparte, a lo largo de la vida, las expresiones espaciales y temporales, así como las racionales (símbolos, dogmas y teologías) y las activas (ritos y oración), pues tanto él como María de San José se encuentran insertos en el mismo macrocontexto contrarreformista. Salvando naturalmente las distancias con la vida monacal femenina ${ }^{84}$, a estas mediaciones cabría añadir las expresiones temporales de un calendario litúrgico que habrían sido padecidas por el poeta durante los años en que siente la llamada de Dios.

Estos años de vocación religiosa del dramaturgo madrileño dieron lugar, como es bien sabido, a las Rimas sacras, que nuevamente han hecho correr mucha más tinta (práctica científica) que cualquier poemario escrito por mujeres religiosas (práctica literaria), pese a que estas, frente a él, sí han desarrollado con verdadera plenitud una vida completamente vocacional al servicio de Dios ${ }^{85}$. Por tanto, cabe insistir en dos ideas. Por un lado, desde el patriarcado se acepta la relación directa con Dios a través de la experiencia mística femenina, siempre que no rompa determinadas reglas de comportamiento externo al propio cuerpo ${ }^{86}$, es decir, siempre que tenga lugar en el silencio de la privacidad de la propia mujer o, en su defecto, de las paredes del convento y no cause revuelo alguno en el exterior. Simultáneamente, por otro lado, se refuta la capacidad autónoma

83 Cf. J. Martín Velasco, 2006, op. cit., pp. 226-239.

84 Cf. J. Lewandowska, 2013, op. cit., p. 24.

85 Cf. S. Robles Rivera, 2018, op. cit., p. 66.

86 La observación expuesta en J. Martín Velasco, 2009, op. cit., p.68, que defiende la superior cantidad de hombres que padecen fenómenos de levitación, puede explicarse, desde la perspectiva de género, aludiendo a la necesidad de no llamar la atención sobre lo divinamente sobrenatural que puede afectar al cuerpo de las mujeres. De hecho, la misma santa Teresa, al experimentar algunos de sus éxtasis en público, llega a suplicar a Dios «que no quisiese ya darme más mercedes que tuviesen muestras exteriores; porque yo estaba cansada ya de andar en tanta cuenta» (Vida 20:5). Es consciente, por tanto, de que le conviene vivir su fe discretamente, dentro de las paredes del convento y sin crear demasiados revuelos en el exterior. Esta hipótesis podría explicar que no hubiera tantos registros de experiencias similares femeninas como masculinas por miedo, básicamente, a la Inquisición. Véanse, a este respecto, T. Forcades i Vila, 2011, op. cit.; M. P. Manero Sorolla, 1992, op. cit., pp. 512-513; J. Lewandowska, 2019, op. cit., \$3.2.5. 
de la mujer para desenvolverse con éxito en un mundo que se sabe de hombres, lo que en la práctica científica se traduce en el rechazo de una visión pragmática del ser carmelita, como la que expresa María de San José Salazar en nuestro soneto y otros tantos textos suyos en prosa (cf. supra, $\$ 2)^{87}$.

En otras palabras, en el soneto de la religiosa que estamos comparando con el de Lope no hay grandes exaltaciones a lo divino, ni formas extraordinarias de expresar el fenómeno místico que permitan una comparación con los versos más extraordinarios de santa Teresa o, en su defecto, con los arrobamientos amorosos que parece expresar el poema lopesco. Se pretende, simplemente, plasmar por escrito la manera en que debe vivir una sororidad que tiene los pies en la tierra y el corazón en el cielo, pues son perfectamente capaces de gestionar conventos cubriendo todas las necesidades físicas de su plantilla y, a la vez, experimentar las más profundas vivencias místicas en sus cuerpos ${ }^{88}$. En definitiva, la práctica científica viene a confirmar que la práctica literaria no vale nada cuando se forja a partir de la práctica religiosa de una mujer, mientras que lo puede llegar a ser todo cuando proviene de la pluma de un hombre.

En efecto, ambos autores expresan en sus textos la experiencia vivida, en tanto representan sendas autobiografías desde una visión deóntica que no se centra, pues, en cómo es la vida que defienden sino en cómo debe ser el ideal que se marcan como objetivo esencial de sus respectivas existencias. Ambas experiencias, entonces, deberían generar conocimiento de una importancia similar (recuérdese la relevancia epistemológica que toda vivencia ofrece ${ }^{89}$ ), pero no lo hacen: el soneto de la mujer queda relegado como objeto de estudio, simplemente, por centrar su contenido en la práctica (religiosa) femenina, por ser capaz de combinar lo ideal del espíritu del cristianismo con lo real de la época en que le tocó vivir,

87 Cf. M. P. Manero Sorolla, 1992, op. cit.

88 Cf. P. S. Anderson, 2004, op. cit.; A. Hollywood, 2004, op. cit.; H. Walton, 2004, op. cit.; J. Martín Velasco, 2006, op. cit.; 2009, op. cit.; N. Bueno-Gómez, 2018, op. cit.; 2019, op. cit.

89 Como explican, por ejemplo, M. A. García de León Álvarez, «Género, poder y conocimiento. Para una biografía intelectual desde las ciencias sociales y la perspectiva de género", Investigaciones Feministas 7 (2) (2016), 159-177 y S. Robles Rivera, 2018, op. cit., pp. 74-75. 
mientras la obra de Lope de Vega atraviesa fronteras y tiempos desde que se concibe ${ }^{90}$.

\section{MOTIVOS INTRADISCURSIVOS: LA PRÁCTICA LITERARIA FEMENINA COMO PRÁCTICA INCLUSIVA.}

En este apartado se va a efectuar el análisis de los textos desde una perspectiva intradiscursiva siguiendo las seis llaves de la cultura de Díaz de Rada (2010), pues permiten atender a la interrelación que se produce entre las peculiaridades lingüísticas de cada poema, producto final de la práctica literaria, y la función comunicativa que desempeña dentro del contexto sociocultural en que se compone: 1) universal-concreto; 2) acción-relación; 3) holismo; 4) estructura-proceso; 5) sujeto-agente; y 6) individuo-en-relación.

Así, la primera llave contiene la oposición universal-concreto, que asume que la cultura, como elemento humano universal, se configura en prácticas concretas $^{91}$. La diferencia entre el texto masculino y el texto femenino que nos ocupan se encuentra, precisamente, en que el primero asume como universal algo que es en realidad particular (concretamente, masculino), mientras que la segunda admite la universalidad del Dios cristiano, pero siempre ligada a la concreción de las reglas comportamentales establecidas en su comunidad religiosa.

En efecto, la sentencia final del poema de Lope universaliza, sin lugar a la discrepancia, una experiencia que sin duda alguna es personal o que, si acaso, puede ser también sociocultural («esto es amor; quien lo probó, lo sabe»). Es posible que haya lectores (coetáneos a él o no) que se sientan plenamente identificados con este texto y compartan lo que en él se dice como descriptor válido para el sentimiento del amor; pero igualmente puede haber lectoras a las que se les escape esta interpretación y la vean quizá demasiado superficial, tal vez por estar codificada androcéntricamente ${ }^{92}$. A esta manera de concebir el mundo es a la que cabe referirse cuando se deja entrever que el hombre «no es capaz de comprender» a la mujer, sencillamente, porque da por hecho que lo que él escribe tiene que ser igualmente válido para ella(s), sin siquiera haberse molestado en

90 Cf. A. Alonso, 1952, op. cit.; G. L. Guitarte, 1977, op. cit.

91 Estamos siguiendo a A. Díaz de Rada, 2010, op. cit., 82.

92 Cf. A. Steffanell, 2010, op. cit., pp. 123-125; C. A. Andrade Mello, 2011, op. cit. 
preguntarle(s). Busca, en definitiva, dar forma intelectual a través del logos a una experiencia masculina que solo puede entenderse desde lo visceral del alma y, al hacerlo, es universalizada ${ }^{93}$, en tanto el concepto de andrós se tiende a asimilar, en la ideología de género típicamente patriarcal, al de ánthropos ${ }^{94}$.

La aspiración de la poeta, sin embargo, es más modesta. En primer lugar, el último verso que da sentido a todo el poema («esto es ser carmelita reformada») solo afecta a las carmelitas reformadas, sin aspiración universal, pues comprende un grupo muy reducido de la orden del Carmelo (la sección femenina) y, dentro de esta, de las descalzas (lo que entonces excluye a las calzadas). En segundo lugar, no pretende afirmar rotundamente una verdad universal basada en la experiencia individual, sino sugerir una forma de vida para quienes deseen formar parte de su comunidad. Asimismo, no trata de alcanzar a todo el ser humano apelando a su forma de entender a Dios; tan solo pretende defender que, si se quiere seguir la doctrina de santa Teresa, ha de hacerse de determinada manera. Su poema recoge, pues, una esencia comportamental que se convierte en identidad individual a través de la comunidad; el poema del Fénix recoge una descripción de un sentimiento construido en la sociocultura del momento, que se convierte en una verdad indiscutiblemente universal al ser descrita desde el conocimiento que da la experiencia individual ${ }^{95}$.

Esta manera de experimentar en la propia carne nos lleva analíticamente a la sexta llave, el individuo-en-relación, que implica el concepto

93 Cf. G. L. Guitarte, 1977, op. cit.

94 Los trabajos feministas que confirman esta tendencia a la universalización son numerosos. Destacamos los que más se ajustan conceptualmente a los objetivos aquí propuestos: N. Frankenberry, «Feminist approaches», 2004, op. cit., p. 17; H. Walton, 2004, op. cit., p. 130; L. Ramón, 2010, op. cit.; L. Posada Kubissa, 2015, op. cit., pp. 109-117.

95 A modo meramente anecdótico y teniendo en cuenta los adjetivos de los poemas, la última palabra del soneto de María está en femenino («reformada»), pese a que podría haber concordado en el masculino genérico (término no marcado) con "carmelita» si se hubiera buscado algún tipo de universalización indiferente a la identidad de género que ella parece mostrar con dicha forma gramatical. En el caso del texto de Lope, el género no marcado en todos los adjetivos cabe entenderse bien como complemento del sustantivo amor, que es masculino; bien como caracterizador universalizante de una experiencia particular; bien como atributo de la voz poética masculina, dado que las dos largas listas de adjetivos propuestos dependen de verbos que denotan estados («estar» $\mathrm{y}$ «mostrarse») y que, además, necesitan implícitamente agentes (masculinos) que padezcan dichos estados. 
antropológico de persona en tanto ser-en-relación-con-otros, en tanto forma social de la expresión pública mediada por el cuerpo biológico ${ }^{96}$. La diferencia entre los textos se encuentra en que la identidad femenina se construye en comunidad y se mantiene por el amor a Dios ${ }^{97}$, pues ella no puede ser sin ser monja, mientras que la identidad masculina olvida al otro, ensalzando la figura del más puro yo individual y anteponiéndola a cualquier otra configuración del concepto de persona.

El concepto de amor que ofrece el texto lopesco, pues, está situado de manera radical en un individualismo idealizado, que permite al sentimiento operar solo desde dentro de uno mismo, como si no hubiera un tú o, de haberlo, estuviera totalmente alienado (cf. supra, \$3.2), como si no hubiera ninguna relación con ningún otro. El empleo constante del singular como número no marcado en todos los adjetivos del soneto puede hacer pensar en una tendencia individualista que contribuye a caracterizar el mismo sentimiento del amor desde una perspectiva puramente androcéntrica ${ }^{98}$. Asimismo, que toda la descripción se centre en una experiencia puramente personal pone al yo por encima de todo, pues lo convierte en el único ser cognoscente capaz de definir con precisión dicho sentimiento tan complejo de verbalizar. En el soneto de María, sin embargo, hay una combinación perfecta entre las consecuencias individuales que conlleva pertenecer a la orden y las características requeridas para encontrar la felicidad en ella. Esta fusión es, entonces, la columna vertebral de su poema, pues la detallada descripción de la vida conventual de las carmelitas descalzas implica una plena conciencia del ser humano como ser social («esto es ser carmelita reformada»).

La segunda llave, el par acción-relación, deja entrever la cultura como un proceso comunicativo, completamente inexistente sin lazos discursivos construidos entre personas ${ }^{99}$. En nuestro caso, la diferencia entre una visión puramente activa y una visión puramente relacional se encuentra en la asunción de una identidad femenina supuestamente pasiva, interesada solamente en fomentar vínculos intersubjetivos de emociones que van más

96 Cf.Á. Díaz de Rada, 2010, op. cit., pp. 98-99. Recuérdese la esencia biopsicosociocultural del ser humano que se defiende en Ramírez Goicoechea, 2009, op. cit.

97 Cf. S. Robles Rivera, 2018, op. cit., p. 86.

98 Cf. C. A. Andrade Mello, 2011, op. cit.

99 Recuérdese nuestra definición de "práctica» expuesta en $\$ 1$; adaptamos, en cualquier caso, lo escrito por Á. Díaz de Rada, 2010, op. cit., p. 84. 
allá de lo meramente humano ${ }^{100}$, y una identidad masculina considerada activa, que solo busca el pleno ejercicio del hacer físico ${ }^{101}$.

En un primer momento, esta diferencia puede comprobarse en la ya mencionada estrategia que cada uno desempeña para rematar su texto. María de San José opta por dejar dicho, en el último verso, a qué se está refiriendo con todo lo descrito y narrado anteriormente, de manera que objetivamente une un pronombre demostrativo como "esto" (que adopta un significado claramente deíctico-textual y refiere al contenido de los trece versos anteriores) con su atributo esencial («ser carmelita reformada»), mediante el verbo copulativo ser en tercera persona de singular del presente de indicativo («es»). Su identidad es límpidamente relacional; su vínculo con la comunidad es la esencia ontológica de su propia existencia: ser carmelita reformada se encuentra en lo más profundo de su persona. Su ser es su relación con la comunidad carmelita. Su religión es su vida. Ella no puede no ser carmelita reformada porque, entonces, simplemente, dejaría de ser. No concibe otro modo de existir.

La visión de Lope de Vega, por el contrario, no focaliza el significado de su existencia en el ser o el no ser, sino en el experimentar, en la pura acción. La visión masculina del mundo se plasma en la última de las dos oraciones que componen el decimocuarto verso. En efecto, la primera es claramente paralela a la de María de San José («esto es amor»), en el sentido de que emplea igualmente el mismo pronombre demostrativo ("esto») con significado deíctico-textual para hacer alusión a lo que se acaba de describir-narrar en el discurso, aclarando así que todo él se refiere a un sentimiento claramente humano como es el amor. La segunda frase de este verso parece una aserción indiscutible («quien lo probó, lo sabe»), para la que no cabe ningún tipo de reproche, porque está basada plenamente en la propia experiencia ${ }^{102}$. Esta, mediante el pronombre relativo sin antecedente «quien», permite ser extrapolada a todos aquellos (seguramente varones) que hayan sentido lo mismo. El círculo argumentativo, pues, queda plenamente cerrado: si alguien no sabe que lo que él define es el amor, es porque no lo ha experimentado; si lo ha experimentado, necesariamente concordará con el poeta en el sentido de su soneto, porque parece que es

100 Cf. S. Robles Rivera, 2018, op. cit., pp. 86-87.

101 Cf. C. A. Andrade Mello, 2011, op. cit., pp. 25-26.

102 Cf. M. A. García de León Álvarez, 2016, op. cit. 
una verdad universal e indiscutible ${ }^{103}$. Y si no se está de acuerdo con él, es porque lo que ha sentido dicha persona discordante no era amor. Parece clara, pues, la interrelación entre las tres llaves (universal-concreto, acciónrelación, individuo-en-relación).

Frente a esta interpretación, se puede comprobar que la identidad femenina del soneto de María de San José se caracteriza por los dos tipos de disposición ante la vida que bien podrían ser los atributos típicos de la existencia religiosa («conforme a Dios»), encarnada en la visión pasiva y activa de las bíblicas Marta y María: en los cuartetos priman los sintagmas nominales que denotan descripción-contemplación (María), mientras que en los tercetos abundan los sintagmas verbales que implican narraciónacción (Marta) ${ }^{104}$. En dicha primera parte, se establecen las directrices de la recientemente reformada orden del Carmelo: pobreza ("pobre el vestido»), limpieza («[vestido] limpio sin cuidado»), amabilidad («un rostro afable»), sinceridad y humildad («un trato honroso, sincero y modesto»). En la segunda parte, se focaliza la información en los objetivos de la vida religiosa, entre los que, naturalmente, se encuentra la oración («buscar a Dios por solo ser Dios bueno»), la austeridad («abrazar con el alma la pobreza»), la obediencia («tener por libertad el ser mandada»), la gracia de Dios («tener] el corazón vacío, de Dios lleno») y la modestia («conocer la soberbia en su bajeza»). En el texto de María de San José hay, por tanto, tanta relación (con Dios, con otras carmelitas, consigo misma) como acción (buscar a Dios, decidir ser pobre, aceptar la obediencia), aunque el imaginario patriarcal construido sobre la misma imagen de la mujer ha hecho triunfar una (auto)percepción femenina más centrada en la primera que en la segunda ${ }^{105}$.

Similarmente, el varón prototípico tiende a jactarse de activo, cuando en la primera parte del poema abundan las expresiones pasivas. Así, la identidad masculina de Lope de Vega se plasma en la constante antonimia

103 Cf. G. L. Guitarte, 1977, op. cit.

104 Como recuerda P. Fernández Martín, 2020, op. cit., pp. 158-159, esta distinción entre la vida activa de Marta y la vida contemplativa de María la tiene muy en cuenta Teresa de Ávila: «Así que [el alma] está casi obrando juntamente en vida activa [Marta] y contemplativa [María], y entender en obras de caridad y negocios que convengan a su estado, y leer, aunque no del todo están señores de sí, y entienden bien que está la mejor parte del alma en otro cabo» (Vida, 17:4).

105 Cf. C. Servén Díez, 2008, op. cit., p. 9. 
que se produce en los conceptos propuestos para definir los efectos del amor humano al que hace referencia desde el principio. El primer cuarteto, aunque comienza con dos infinitivos («desmayarse» y «atreverse»), está plagado de adjetivos dependientes del tercer infinitivo, «estar», el verbo estático por antonomasia en la lengua española, lo que implica un claro enfoque descriptivo-contemplativo («furioso, / áspero, tierno, liberal, esquivo, / alentado, mortal, difunto, vivo, / leal, traidor, cobarde y animoso»). Igualmente, el siguiente cuarteto comienza con un infinitivo negado («no hallar fuera del bien centro y reposo»), y nuevamente se emplea un verbo semicopulativo como «mostrarse» para otorgar al lector una detallada descripción de las cualidades que produce el amor en él («alegre, triste, humilde, altivo, / enojado, valiente, fugitivo, / satisfecho, ofendido, receloso»). Tan solo es en los dos tercetos donde se dan los infinitivos que dotan al texto del valor semántico de la narración-acción, tal vez para equilibrar dicha descripción-contemplación. De este modo, amar, para la voz poética, es no desear dejarse engañar ("huir el rostro al claro desengaño»); creer que se está experimentando un beneficio que en realidad es perjudicial («beber veneno por licor suave»); ser feliz en la desdicha que ahuyenta el gozo («olvidar el provecho, amar el daño»); conjugar lo más sublime de la experiencia amorosa con lo más abominable ("creer que un cielo en un infierno cabe») y, naturalmente, entregarse de forma absoluta al amado de una manera que no tiene por qué ser correspondida («dar la vida y el alma a un desengaño»).

Así, mientras la escritora está describiendo las pautas ideales de conducta que debe llevar toda buena carmelita reformada, aludiendo en una primera parte a una manera de ser y en una segunda parte a una forma de actuar, el poeta llena el texto de sintagmas que califican metonímicamente al amor («esto es amor») y apela a la experiencia (propia y ajena) para defender su descripción-acción como un hecho completamente irrefutable («quien lo probó, lo sabe»). Ella no muestra contradicción alguna entre ser y no ser carmelita, pues forma parte de una austera esencia existencial que es en la que se encuentra sinceramente configurada su identidad; él, sin embargo, como ya se ha seńalado (cf. supra, \$3.2), cae de lleno en el tipo de «literatura que celebra y reprueba el amor al mismo tiempo» ${ }^{106}$, construida sobre la

106 Cf. L. Funes, 2018, op. cit., p. 104. 
base ideológica del amor cortés ${ }^{107}$, que permite jugar con el objeto deseado haciéndole creer que realmente está por encima del sujeto amante, cuando, en la realidad, evidentemente, no es así.

La oposición acción-relación está directamente relacionada con la quinta llave, sujeto-agente, pues ambos escritores se encuentran sujetos a las reglas socioculturales y ambos son, a la vez, agentes responsables de sus respectivos comportamientos ${ }^{108}$. La diferencia está en la libertad real que cada uno de ellos tiene derecho a ejercer para llevar a cabo sus prácticas (científicas y literarias) en tanto agentes socioculturales e, inversamente, en el grado de opresión que le supone a cada uno ser sujeto de sus respectivos contextos sociohistóricos ${ }^{109}$.

Así, parece claro que María de San José se halla relacionalmente sujeta a $\operatorname{Dios}^{110}$, quien es la esencia que guía su comportamiento religioso («conforme a Dios») y al que, procurador de la ansiada felicidad («un rostro afable»; «un valeroso pecho al bien atado», «el corazón vacío, de Dios lleno»), cabe abandonarse sin remedio, confiando en su infinita bondad ("por solo ser Dios bueno»), tan diferente a la del ser humano («en todo al hombre opuesto»). A la vez, ella resulta ser agente de sus propias acciones en tanto decide llevar a término las acciones plasmadas gramaticalmente en los infinitivos como «buscar a Dios» o "abrazar con el alma la pobreza» y entender que, en el servirle, se encuentra la propia libertad («tener por libertad el ser mandada»). Se conjuga en ella, pues, la paradoja de haber sido libre para elegir a quién servir en una época en la que las mujeres son capaces de convertir la vida conventual en una vida plagada de libertad, no tanto porque ellas no puedan salir del recinto, sino más bien porque nadie puede entrar para dominarlas ${ }^{111}$.

107 Cf. G. L. Guitarte, 1977, op. cit. Recuérdese que «ideológica» mantiene el significado dado en $\$ 3.2$ a «ideología», en línea con lo expuesto en J. Verschueren, 2013, op. cit., pp. 7-20.

108 Cf. Á. Díaz de Rada, 2010, op. cit., pp. 94-98.

109 Cf. T. López Pardina, 2015, op. cit.

110 Cf. S. Robles Rivera, 2018, op. cit., pp. 83-84.

111 Cf. F. Villanueva Lavín, "Creedme vosotras y no os engañe nadie” en S. Bara Bancel (ed.), Mujeres, mistica y politica. La experiencia de Dios que implica y complica, Navarra: Verbo Divino, 2016, pp. 139-176; J. Lewandowska, 2013, op. cit., pp. 17-18; J. Lewandowska, 2019, op. cit., cap. 1. 
Muchos más verbos aparecen en el poema de Lope de Vega, la mayoría de ellos con valor atributivo, como ya se ha indicado, pero que, en cualquier caso, guían la acción del texto y convierten al autor lingüísticamente en un claro agente («Desmayarse, atreverse»; "no hallar fuera del bien centro y reposo"; "huir el rostro al claro desengaño, / beber veneno por licor suave, / olvidar el provecho, amar el dańo; / creer que un cielo en un infierno cabe, / dar la vida y el alma a un desengaño»). No obstante, no deja de estar sujeto al mundo y, en mínima instancia, a una realidad sociocultural, en tanto verbaliza la esencia completamente terrenal (en el sentido de realista, perceptible exclusivamente por los sentidos) de un concepto de amor que pende, por completo, de los valores atribuidos en la época a lo que suponía la relación hombre-mujer ${ }^{112}$.

Cuando el binomio acción-relación, ya mencionado, se inserta en un tejido institucional más amplio, se puede acceder fácilmente a la cuarta llave de la sociocultura, el par estructura-proceso. Esta oposición contribuye a comprender que toda práctica sociocultural se concibe en constante movimiento, solo ficticiamente detenido durante los instantes en los que la práctica-proceso se convierte en imagen-estructura ${ }^{113}$. En este caso, la diferencia entre los dos textos se encuentra en la estaticidad del poema masculino, que (recuérdese) esencializa la pasión amorosa por reducir toda su experiencia al simple sustantivo abstracto amor, frente a la dinamicidad del femenino, que entiende la esencia de la pertenencia a la comunidad religiosa como una forma de vida que, por serlo, debe alcanzar todo su tiempo vital.

La primera toma forma en el ansia lopesca de describir tan solo una fase del proceso amoroso. Si desde una perspectiva realista se pretende abarcar, para alcanzar a comprender, toda la práctica sociocultural que una relación interpersonal conlleva ${ }^{114}$, habría que analizar todo el fenómeno amoroso desde que surge la pasión hasta que se desvanece por completo (o hasta que mueren los amantes). Tal y como está redactado, la voz lírica del soneto de Lope de Vega pone el foco exclusivamente en la primera fase del amor, invisibilizando así cualquier sentir negativo que acarree llegar a cualquier otra de sus numerosas fases. El sufrimiento al que el poeta se

112 Cf. C. A. Andrade Mello, 2018, op. cit.; L. Funes, 2018, op. cit.

113 Cf. Á. Díaz de Rada, 2010, op. cit., pp. 88-94.

114 Cf. Á. Díaz de Rada, 2010, op. cit., pp. 81-116. 
refiere («ofendido, receloso», «huir el rostro al claro desengaño», «beber veneno por licor suave») no hace alusión al final de la relación, sino al falso comienzo que indica el no ser correspondido, por lo que cabe asumir que se está centrando exclusivamente en el sentimiento de una etapa inicial.

Ella, por el contrario, muestra en los cuartetos una panorámica en movimiento del ser carmelita, en los que describe cómo es el proceso de ser religiosa mientras se está siendo ("pobre el vestido»; «un rostro afable, grave, alegre, honesto, / un trato honroso, sincero y modesto"); y ofrece una instantánea centrada en la primera fase de la práctica religiosa (lo que podría considerarse la profesión de fe) que plasma en los tercetos del resultado de su práctica literaria: primero, se debe desear acceder a Dios («buscar a Dios por solo ser Dios bueno»); después, se tienen que aceptar los votos de pobreza («abrazar con el alma la pobreza») y obediencia («tener por libertad el ser mandada»); a continuación, conviene dejarse llevar por la bondad divina («[tener] el corazón vacío, de Dios lleno») y, finalmente, se han de evitar pecados como el orgullo ("conocer la soberbia en su bajeza»).

Naturalmente, ambos poetas expresan sus respectivas experiencias vitales por medio de un poema que funciona, entonces, como un fotograma (práctica literaria) extraído de un vídeo (práctica científica), que permite dar a conocer al espectador-lector tan solo una parte de la completa práctica axiológica. Dicha interrelación entre la práctica literaria y la práctica científica culmina, sin duda, en el holismo de la tercera llave de la práctica sociocultural, que nos permite establecer una relación entre las llaves aquí empleadas para entender el poema como práctica literaria, sus autores y las instituciones sociales en que se inserta la intertextualidad que los caracteriza ${ }^{115}$.

En efecto, si ambos poemas representan la vida de sus respectivos escritores, cabe entonces entrelazar su experiencia directa (que toma forma aquí en la práctica literaria analizada) con el concepto de conocimiento que de ella puede desprenderse (que toma forma en la práctica científica que a lo largo de los siglos ha analizado la susodicha práctica literaria): ella, religiosa de una profunda fe, carmelita reformada, vivió para defender a capa y espada la herencia de una forma de vida espiritual que contrastaba con la esgrimida por los que no apoyaban las fundaciones teresianas, sin escapar de la institución eclesiástica a la que pertenecía desde que

115 Cf. Á. Díaz de Rada, 2010, op. cit., pp. 86-88. 
profesó; él, apasionado vividor del amor humano y divino, plasmó magistralmente cada momento de su autobiografía en la extraordinaria y prolífera diversidad de textos que compuso, sin tampoco poder huir de las circunstancias socioeconómicas de su origen burgués que constantemente tuvo que afrontar.

En términos holísticos, pues, el poema lopesco se caracteriza por una tendencia al universalismo que asume como indiscutible una experiencia de alcance personal o, si acaso, sociocultural (primera llave) que es el reflejo, paradójicamente, de un individualismo construido sobre las apariencias del androcentrismo reinante en su misma sociocultura (sexta llave), en la que el único que parece ser agente (quinta llave) de acción (segunda llave) de toda práctica sociocultural, especialmente de todo sentir amoroso, es el hombre, capaz, a su vez, de estructurar en una exclusiva instantánea (cuarta llave) todo un proceso de interrelaciones humanas.

Frente a esto, el poema de María de San José Salazar se puede analizar echando mano de las seis llaves de la cultura sin crear en ellas haces de opuestos. En efecto, el soneto de María se caracteriza por ser concreto y universal a la vez (primera llave), pues, por un lado, ofrece «la verdad» de Dios como esencia de vida, pero, por otro lado, no desea imponérsela a todos los seres humanos, sino marcarla como modelo de vida a quienes hayan ya decidido seguirla para formar parte de su comunidad religiosa. Es precisamente el susodicho Dios quien, de similar manera, la obliga a estar sujeta (sexta llave) y, a la vez, ser su agente (quinta llave) en el mundo terrenal, pues ella ha decidido libremente servirle y cambiar, por tanto, al varón por él. Esta forma de vida, típica del Carmelo teresiano del que María de San José es pura heredera, conjuga a la perfección la vida contemplativa y la vida activa (segunda llave), lo que rechaza de lleno el concepto de pasividad típicamente aplicado a la conducta femenina ${ }^{116}$. Finalmente, aunque su soneto es también una instantánea (cuarta llave) de todo el proceso del «ser carmelita reformada», simultáneamente muestra una panorámica de su práctica religiosa al completo, que abarca diversas acciones de las que el encuentro con Dios es solo el principio ${ }^{117}$. La peculiaridad de su combinación intenta recoger toda una diversidad de

116 Cf. C.A. Andrade Mello, 2011, op. cit., pp. 25-26.

117 Cf. S. Robles Rivera, 2018, op. cit., p. 75. 
experiencias físicas y metafísicas, sin dejar de ser concreta e impidiendo que se diluya en lo universal.

La llave que falta, la tercera, permite una interpretación holística que engarza la práctica científica con la práctica literaria. Así, mientras el poema de Lope de Vega cumple a rajatabla con los principales elementos atribuidos al androcentrismo histórico, esto es, individualismo, afán de universalidad, agente activo y estructura estáticamente concebida, el soneto de Salazar ofrece una intersección entre todos ellos que constituyen, inclusivamente, una correlación de categorías que no solo permiten entender la riqueza de su propuesta vital en los mencionados catorce versos, sino que, además, contribuyen a entender los motivos por los que, desde la perspectiva intradiscursiva, su poema no ha sido tenido en cuenta en la práctica científica.

\section{Síntesis Final.}

Desde una perspectiva superficial que considere en exclusiva el macrocontexto sociohistórico en que se produce un texto literario, se puede fácilmente comprobar que la diferencia en la comparabilidad entre un soneto como "Desmayarse, atreverse, estar furioso» de Lope de Vega (1562-1635) y "Pobre el vestido, limpio, sin cuidado" de María de San José Salazar (1548-1603) se debe solamente al género de sus autores, pues ambos son relativamente coetáneos (ella es tan solo catorce años mayor que él) y habitantes de un espacio similar (distintos puntos de la España áurea); pertenecen originariamente a una clase social comparable y hablan una variedad lingüística probablemente muy próxima.

Sin embargo, según se va profundizando en la comparación de los textos se van descubriendo no solo las diferencias sino también cómo estas han sido tácitamente ocultadas por siglos de historia de la literatura logofalocentrista (cf. supra, \$2). Así, al analizar el entorno que rodea a la situación comunicativa de cada poema, se puede comenzar distinguiendo la intencionalidad didáctica del soneto de María, en línea con otros textos suyos, frente a la intencionalidad plenamente amorosa, presuntuosa si cabe, del soneto de Félix.

La aceptabilidad que ha logrado cada texto es igualmente distinta. Desde la práctica literaria, los textos de la mujer serían plenamente aceptados en el convento lisboeta para cuyas religiosas fueran seguramente 
redactados, mientras que él intentaría desde el principio hacerlos públicos, lo que equivale a defender que tenía en mente cualquier lector cortesano interesado en su contenido. Desde la práctica científica, los textos femeninos no contaron con mayor valor, precisamente, por moverse en exclusivos círculos privados (conventuales), mientras que él, al publicarlos en 1602, pasaría a formar parte del canon literario casi de forma inmediata. Esto es determinante para la relevancia informativa que supuso, durante los siguientes años (e incluso siglos), la voz poética del dramaturgo frente a la silenciada voz de María de San José.

Esta diferencia en el grado de informatividad de cada texto y, en general, de cada poeta, se debe a la persistente existencia a lo largo de la historia de la literatura de lo que se podrían considerar tres mitos epistemológicos, directamente relacionados con los tres motivos extradiscursivos de la concepción androcéntrica de la gnoseología (cf. supra, \$3).

El primer mito pasa por esencializar la práctica literaria, despojando su producto textual de todo rasgo sociocultural. El éxito de esta idea se encuentra en la consideración descontextualizada del texto que se ha defendido desde la práctica científica, que en el fondo da por hecho que si un poema determinado ha resultado irrelevante durante siglos es porque no cumple con los requisitos formales o estéticos de los textos literarios objetivamente buenos, no porque sus autoras hayan sido una y otra vez invisibilizadas.

Bien al contrario, se ha defendido aquí la necesidad de comprender toda epistemología como anclada a un espacio-tiempo concreto, lo que ha implicado la existencia de numerosas mujeres intelectualmente brillantes ocultadas solamente por el hecho de ser mujeres y de no encajar, por tanto, en lo que se espera de ellas desde el patriarcado instalado en la práctica científica (cf. supra, \$3.1).

El segundo mito de la epistemología clásica hace igualmente esencial la misma práctica científica, al defender su más absoluta neutralidad a la hora de establecer los límites entre lo que puede pertenecer al canon literario y lo que no. El uso indiscriminado de la imagen de la mujer o de sus textos con fines puramente políticos (como ocurrió con sor Francisca Josefa de Castillo durante la independencia colombiana y con la misma santa Teresa de Jesús durante la época franquista, por ejemplo), a quienes les interesa una faceta de su persona que, normalmente, no tiene que ver 
con su feminidad, es una buena muestra de la escasa objetividad reinante en la configuración del canon.

Por el contrario, este se forja a partir de un cúmulo de juicios de valor realizados por los distintos estudiosos que se acercan a la práctica literaria desde el sistema axiológico que caracteriza todo el entramado sociocultural al que se encuentran anclados, de manera que, aunque lo pretendan, no son libres de la ideología (de género o de cualquier otro rasgo sociológico con el que se sientan meramente identificados) que actúa sobre su quehacer científico (cf. supra, \$3.2).

El tercer mito, finalmente, esgrime el carácter puramente teórico del conocimiento. Como este ha sido generado en contextos socioculturales concretos por personas de carne y hueso, se ha creado una especie de condicionamiento clásico al permitir la conexión asociativa entre el estímulo de la práctica literaria y la respuesta de la práctica científica. En otras palabras, como solamente a los hombres se los permitía formar parte del colectivo dominante encargado de elegir qué textos conforman el canon literario y cuáles no, eran ellos igualmente los que más herramientas socioculturales (en esencia, acceso a la tradición a través de distintos medios educativos) poseían para aprender a abstraer la información que les iba llegando de las distintas experiencias vividas. Al ser también ellos quienes teorizaban sobre la práctica, el prestigio social de su género hacía las veces de validador universal de lo epistemológicamente aceptable.

Sin embargo, la práctica científica es práctica no solo porque se trate de una conducta humana situada espacio-temporalmente y, por ello, enlazada a un significado intersubjetivamente contextualizado, sino también porque es tradicional, en el sentido de que alberga en su quehacer la manera de actuar de generaciones anteriores. Lo que se ha considerado teoría desde la perspectiva epistemológica no solo no conforma en exclusiva el conocimiento (que también resulta ser práctico) sino que además constituye el conjunto de las experiencias vividas de los que han ejercido la misma práctica científica antes que nosotros, es decir, la teoría del hoy fue la práctica en el pasado. Distinguir radicalmente entre teoría (masculina) y práctica (femenina) y darle a la primera un estatus sociocultural mayor que a la segunda porque, por conexión asociativa, la primera ha sido desarrollada por el género dominante y la segunda, por el género dominado, contribuye erróneamente a oponer de forma radical 
dos formas de hacer que, diacrónicamente, resultan ser la misma. En este contexto, la práctica religiosa típicamente femenina es solo un ejemplo más de lo desterrada que ha estado la manera de entender el mundo de las mujeres, en concreto, de las monjas o de las que, sin serlo, han encontrado en la fe un refugio devocional o toda una Weltanschauung (cf. supra, \$3.3).

A este respecto, la situacionalidad determinante para decidir sobre el valor epistemológico de un poema como el de María de San José (como el de tantas otras mujeres) ha estado marcada por una mujer, Teresa de Cepeda y Ahumada, cuya figura ciertamente ha hecho correr ríos de tinta, no en tanto mujer ni en tanto filósofa-teóloga, sino más bien en tanto mística o, si acaso, escritora. Este marco sociocultural ha influido, entonces, en la necesidad de adoptar un modelo femenino como ejemplo idealizado (por los hombres) del correcto comportamiento en vida que, como "premio», recibe la debida consideración también en muerte. Esto es, la santidad que ha rodeado a la figura de la abulense, fomentada por instancias (masculinas) igualmente políticas ya en su época, ha puesto el nivel de comparabilidad lo suficientemente alto como para que casi ninguna otra mujer pueda alcanzarlo. Y esta extrema idealización ha supuesto, a su vez, un posible sentimiento de culpabilidad en la misma figura femenina a la que muchas anhelan semejarse, sin percatarse de que quienes la elevan a los altares como modelo de vida y obra son esencialmente hombres que nunca habrían hecho algo similar con otro(s) hombre(s). En otras palabras, se ha utilizado la figura teresiana para dejar en la sombra a otras muchas mujeres cuya práctica literaria puede estar a su altura y, además, se ha puesto la carga de la responsabilidad en la misma Teresa, como si ella hubiera elegido voluntariamente ser etiquetada de mística o de escritora, en el invisible proceso de esencialización tanto de la práctica literaria (descontextualización) como de la práctica científica (neutralización de valores).

Todo ello ha influido, naturalmente, en la ausencia de la mujer en el análisis intertextual que de la práctica literaria se ha hecho durante los siglos desde la práctica científica. Como se ha indicado en varias ocasiones a lo largo del texto (cf. supra, \$2), el parecido formal y conceptual entre los sonetos es demasiado profundo como para que nadie haya reparado en él. Si los dos poetas han bebido de una fuente común, quizá ambos deberían ser igualmente reconocidos. Si el texto de Lope ha influido en el de María, 
quizá debería ser entonces también reconocida esta intertextualidad en tanto ella bebe de la fuente discursiva del Fénix de los Ingenios. Si es, en cambio, el soneto de Salazar el que ilumina al del madrileño, cabe entonces preguntarse si, en el caso de que los selectores del canon hubieran llegado a descubrir tal conexión, les habría dado vergüenza reconocer que detrás de tal ingenio hay una práctica literaria femenina que no está descontextualizada, ni es libre de valores, igual que la de él.

En cuanto al microcontexto, equivalente aquí al análisis intradiscursivo (cf. supra, \$4), demuestra un mayor nivel de profundidad en la diferencia entre ellos y permite, incluso, evidenciar que puede haber causas internas al propio poema femenino que faciliten su exclusión del canon literario desde una perspectiva puramente sociocultural. La principal de esas causas es el afán de inclusión y la ausencia de universalización de un contenido que se propone como posible estilo de vida, en una modesta manera de asumir la relación social a través de la identidad común de Dios, sin dar por hecho que sea impuesto a quienes no deseen pertenecer a la sororidad.

Al contrario, el poema de Lope de Vega se centra en el mundo a partir de un yo individual que deja de lado lo social para, directamente, aspirar a lo universal de todos los otros, en un proceso etnocéntricamente patriarcal de invisibilización de quienes no comparten su visión masculina del amor. Su poema es, realmente, un afán de universalizar el amor cortés, desde la visión renacentista del ser humano, por medio de un individualismo que no tiene en cuenta las repercusiones de la idealización para el sujeto/objeto deseado y que, pese a ello, se considera un agente activo que solo centra la esencia conceptual de lo relatado en el inicio del proceso, convirtiendo así todo un sistema sociocultural, por naturaleza dinámico y complejo, en una estructura concebida de manera estática.

La religiosa, como se ha dicho, considera a Dios el centro de su mundo, del cual, pese a todo, no consigue escapar; pone a la comunidad por encima de su yo más personal, al describir las pautas de conducta que constituyen la esencia de su vida conventual y, a la vez, de su propia esencia existencial y admite, finalmente, las limitaciones de su propuesta, que considera válidas exclusivamente para las mujeres que comparten los valores teresianos, es decir, las carmelitas descalzas. La diferencia parece evidente: ella, con humildad, no pretende universalizar un modo de ser, sino describirlo para quienes deseen seguirlo, dando a la vez una sensación 
de claridad expositiva, pautada, ordenada, a modo incluso de normativa, condensando así en unos pocos versos lo que ha desarrollado con mucho mayor detalle en buena parte de su obra en prosa.

La forma de acercarse a ambos textos es, por tanto, la que determina su inclusión o su exclusión del canon literario. Cada lector es, individualmente, el responsable final de la expulsión de las autoras del desarrollo de la práctica científica establecido por convención durante siglos y a quien cabe reprochar la exclusividad de la interpretación de la esencia de los textos. Es a él, cuya identidad se ha ido forjando a lo largo de las centurias en un proceso de comunicación biunívoca con los distintos textos, a quien le corresponde ahora volver la vista atrás, ampliar sus puntos de interés pensando más allá de sí mismo y reconocer a aquellas olvidadas, a aquellas inspiradoras mujeres que, sin duda alguna, desde lo más recóndito de la clausura de sus conventos, deseándolo o no, también desarrollaron escritos que podrían haber contribuido a cambiar el mundo.

\section{REFERENCIAS BIBLIOGRÁFICAS}

Alonso, A. (1952): «Lope de Vega y sus fuentes», Thesaurus: Boletín del Instituto Caro y Cuervo, 48/2, pp. 3-26.

Anderson, P. S. (2004): "An epistemological-ethical approach", en P. S. Anderson y B. Clack (eds.), Feminist Philosophy of Religion. Critical Readings. Nueva York/Oxon: Routledge, pp. 87-102.

Andrade Mello, C. A. (2011): "Impasses do amor cortês», Reverso. Belo Horizonte, 62, pp. 23-28.

Beaugrande, R. y Dressler, W. U. (1997): Introducción a la lingüistica del texto. Barcelona: Ariel.

Blanco Gallardo, V. (2010): «Más allá de Occidente. Lo que la Antropología puede enseñar a la Filosofía», Claridades. Revista de filosofía, 2, pp. 93-127. http://dx.doi.org/10.24310/Claridadescrf.v2i0.3930

Bohannan, L. (1966): "Shakespeare in the Bush. An American anthropologist set out to study the Tiv of West Africa and was taught the true meaning of Hamlet», Natural History, 75, pp. 28-33. http://www. naturalhistorymag.com/picks-from-the-past/12476/shakespeare-in-thebush 
Bueno-Gómez, N. (2019): “I Desire to Suffer, Lord, because Thou didst Suffer": Teresa of Avila on Suffering», Hypatia. A Journal of Feminist Philospohy, 34:4, 2019, pp. 755-776. https://doi.org/10.1111/hypa.12488

Bueno-Gómez, N. (2018): «Self-management and Narrativity in Teresa of Avila's work», Life Writing, 15(3), pp. 305-320. DOI: 10.1080/14484528.2018.1475001

Darbord, M. (1994): "Ascéticos y místicos», en J. Canavaggio (dir.), Historia de la Literatura Española. Tomo II. El siglo XVI. Barcelona: Ariel, pp. 149-178.

Denny, J. P. (2013): «El pensamiento racional en la cultura oral y la descontextualización escrita», en D. R. Olson y N. Torrance (comps.), Cultura escrita y oralidad. Barcelona: Gedisa, pp. 95-126.

Dewey, J. (2008): El arte como experiencia. Barcelona: Paidós.

Díaz de Rada, Á. (2010): Cultura, antropología y otras tonterías. Madrid: Trotta.

Díez, J. A. y Moulines, C. U. (2008): Fundamentos de Filosofía de la Ciencia. Barcelona: Ariel.

Eco, U. (1993): Lector in fabula. La cooperación interpretativa en el texto narrativo. Barcelona: Lumen.

Fernández Martín, P. (2021): «Discurso feminista colombiano preilustrado: la imagen femenina en la Vida de Sor Francisca de la Concepción», Revista Cultura \& Religión, XV (1), pp. 109-146. https:// www.revistaculturayreligion.cl/index.php/revistaculturayreligion/article/ view/997

Fernández Martín, P. (2020): «Conocimiento, poder y religión: hacia una consideración de la mística teresiana como discurso teológicofilosófico», Investigaciones Feministas 11 (1), pp. 155-165. https://doi. org/10.5209/infe.65806

Fernández Martín, P. (2019): «La deixis personal en algunas cartas de Rosalía de Castro y Emilia Pardo Bazán desde la gramática funcional del discurso", Madrygal. Revista De Estudios Gallegos, 22, pp. 135-159. https:// doi.org/10.5209/madr.66856

Figueiredo, F. de (1928): Camoens. Vol. III (trad. Marqués de Lozoya). Madrid: Voluntad. https://bibliotecadigital.jcyl.es/es/catalogo_imagenes/ grupo.cmd?path=10068663. 
Forcades i Vila, T. (2011): La teología feminista en la historia. Barcelona: Fragmenta.

Frankenberry, N. (2004): «Feminist approaches», P. S. Anderson y B. Clack (eds.), Feminist Philosophy of Religion. Critical Readings. Nueva York/ Oxon: Routledge, pp. 3-27.

Funes, L. (2018): «Hacia Celestina: paradojas del ideal amoroso cortesano en los textos sentimentales castellanos», Letras, 77, pp. 97-106. http://erevistas.uca.edu.ar/index.php/LET/article/view/1713/1602

García de León Álvarez, M. A. (2016): «Género, poder y conocimiento. Para una biografía intelectual desde las ciencias sociales y la perspectiva de género", Investigaciones Feministas 7 (2), pp. 159-177. https://doi. org/10.5209/INFE.53780

Guitarte, G. L. (1977): «La sensibilidad de Lope de Vega a la voz humana», Anuario de Letras: Lingüistica y filología, 16, pp. 165-195.

Hollywood, A. (2004): «Practice, Belief and Feminist Philosophy of Religion», en P. S. Anderson y B. Clack, Feminist Philosophy of Religion. Critical Readings, Nueva York/Oxon: Routledge, pp. 225-240.

Jesús, Teresa de (1562/2014): El libro de la vida (ed. Fidel Sebastián Mediavilla). Madrid: Espasa/RAE.

Kuper, A. (2001): Cultura. La versión de los antropólogos. Barcelona: Paidós.

Labertit, A. (1994): «El nuevo esplendor de la poesía», en J. Canavaggio (dir.), Historia de la Literatura Española. Tomo II. El siglo XVI. Barcelona: Ariel, pp. 179-204.

Lewandowska, J. (2013): «(Des)alienar las voces femeninas del convento: "la celda propia" de Sor Marcela de San Félix", Itinerarios. Revista de estudios lingüisticos, literarios, históricos y antropológicos, 18, pp. 11-34.

Lewandowska, J. (2019): Escritoras monjas: autoridad y autoría en la escritura conventual femenina de los Siglos de Oro. Madrid/Frankfurt: Iberoamericana/Vervuert.

Llamedo González, J. J. (2018): Teología de Teresa de Jesús. Doctora de la Iglesia. Una visión sistematizada. Madrid: San Pablo.

Lope de Vega, F. (1992): Poesía. Antología (ed. M. García-Posada). Madrid: Espasa Calpe. 
López Pardina, T. (2015): «El cuerpo de las mujeres como locus de opresión/represión», Investigaciones Feministas, 6, pp. 60-68. https://doi. org/10.5209/rev_INFE.2015.v6.51379

Manero Sorolla, M. P. (1992): «Diálogos de carmelitas: Libro de Recreaciones de María de San José», en A. Vilanova (ed.): Actas del X Congreso de la Asociación Internacional de Hispanistas: Barcelona 21-26 de agosto de 1989, Vol. 1, Barcelona: PPU, pp. 501-516. http://www.cervantesvirtual. com/nd/ark:/59851/bmcsj3h5

Manero Sorolla, M. P. (1998): «La Biblia en el Carmelo femenino: la obra de María de San José (Salazar)», en J. Whicker (ed.), Actas del XII Congreso de la Asociación Internacional de Hispanistas: 21-26 de agosto de 1995, Birmingham, Vol. 3, pp. 52-58. https://cvc.cervantes.es/literatura/ aih/pdf/12/aih_12_3_010.pdf

Manero Sorolla, M. P. (1992): «La poesía de María de san José (Salazar)», en Estudios sobre escritoras hispánicas en honor de Georgina Sabat-Rivers. Madrid: Castalia, pp. 187-222.

Martín Velasco, J. (2009): El fenómeno mistico. Estudio comparado. Madrid: Trotta.

Martín Velasco, J. (2006): Introducción a la fenomenología de la religión. Madrid: Trotta.

Morera de Guijarro, J. I. (2017): «Márgenes de la mirada en la mística española» en González García, M. y Sánchez, A.: Renacimiento y Modernidad. Madrid: Tecnos, pp. 439-482.

Morujão, I. (2004): «María de San José (Salazar) OCD, fundadora del primer Carmelo Descalzo femenino en Portugal», Revista de Espiritualidad, 63, pp. 177-211.

Mukařovský, J. (1977): Escritos de estética y semiótica del arte. Barcelona: Gustavo Gili.

Nuño Gómez, L. (2020): El derecho a la educación. Estrategias patriarcales contra la genealogía femenina. Granada: Comares.

Nystrand, M.; Himley, M. y Doyle, A. (1986): The structure of written communication. Studies in Reciprocity between Writers and Readers. Orlando: FL Academic Press.

Olivé, L. (2004): «Normas y valores en la ciencia bajo un enfoque naturalizado», Revista de Filosofía, 29 (2), pp. 43-58. 
Olson, D. R. (2013): «Cultura escrita y objetividad: el surgimiento de la ciencia moderna» en D. R. Olson y N. Torrance (comps.), Cultura escrita y oralidad. Barcelona: Gedisa, pp. 203-222.

Ońate y Zubía, T. (2003): El nacimiento de la Filosofía en Grecia. Viaje al inicio de Occidente. Madrid: Dykinson.

Pascual Elías, R. (2014): María de san José (Salazar). Heredera y transmisora del carisma teresiano. Burgos: Monte Carmelo.

Pedraza Jiménez, F. B. (2009): Lope de Vega. Pasiones, obra y fortuna del «monstruo de naturaleza». Madrid: EDAF.

Posada Kubissa, L. (2015): "Las mujeres son cuerpo: reflexiones feministas», Investigaciones Feministas, 6, pp. 108-121. https://doi. org/10.5209/rev_INFE.2015.v6.51382

Ramírez Goicoechea, E. (2009): Evolución, cultura y complejidad. La humanidad que se hace a si misma. Madrid: CERA.

Ramón, L. (2010): Queremos el pan y las rosas. Emancipación de las mujeres y cristianismo. Madrid: HOAC.

Robles Rivera, S. (2018): «El misterio trinitario en la teología feminista. Reflexiones para una antropología inclusiva», Palabra y Razón, 13, pp. 6390.

Servén Díez, M. ${ }^{a}$ C. (2008): "Canon literario, educación y escritura femenina» en Ocnos: revista de estudios sobre lectura, 4, pp. 7-20. https:// revista.uclm.es/index.php/ocnos/article/view/ocnos_2008.04.01/175

Steffanell, A. (2010): «Sor Francisca Josefa de Castillo (1671-1742): una "rara avis" en el canon de la literatura colombiana fundacional», Cuadernos de Literatura, 14/28, pp. 100-129.

Tanesini, A. (1999): An Introduction to Feminist Epistemologies. Oxford: Blackwell.

Torre, F. de la (1993): Poesía completa (ed. Ma L. Cerrón Puga). Madrid: Cátedra.

Torres Sánchez, C. (2000): La clausura imposible. Conventualismo femenino y expansión contrarreformista. Madrid: Asociación Cultural AlMudayna.

Trapero, M. (1981): «Un tema y dos estilos», Boletín Millares Carlo, 3, pp. 189-204.

Van Dijk, T. A. (2008): Discourse and Context: A Sociocognitive Approach. Cambridge: CUP. 
Van Dijk, T. A. (2011): Sociedady discurso. Barcelona: Gedisa.

Velasco, H. M. (2003): Hablar y pensar, tareas culturales. Temas de Antropología Lingüistica y Antropología Cognitiva. Madrid: UNED.

Verschueren, J. (2013): Ideology in Language Use, Cambridge: Cambridge University Press.

Vicente Rodríguez, J. (2018): María de San José (Salazar). Madrid: San Pablo.

Villanueva Lavín, F. (2016): "Creedme vosotras y no os engañe nadie” en Bara Bancel, S., Mujeres, mistica y politica. La experiencia de Dios que implica y complica. Navarra: Verbo Divino, pp. 139-176.

Walton, H. (2004): «Women writing the divine» en P. S. Anderson y B. Clack, Feminist Philosophy of Religion. Critical Readings. Nueva York/ Oxon: Routledge, pp. 123-135.

Patricia Fernández Martín es Doctora en Lengua Española por la Universidad Complutense de Madrid, Licenciada en Filología Hispánica por la misma universidad y en Lingüística por la Universidad Autónoma de Madrid. También es Licenciada en Antropología Social y Cultural y Graduada en Filosofía por la Universidad Nacional de Educación a Distancia. Tiene asimismo un Máster en Enseñanza del Español como Lengua Extranjera por la Universidad Antonio de Nebrija, otro en Investigación en Lengua Española por la mencionada Universidad Complutense de Madrid.

Lineas de investigación:

- Mujer, filosofía y religión en el Siglo de Oro

- Análisis histórico del discurso en lengua española

- Enseñanza de la lengua española

\section{Publicaciones recientes:}

-«Conocimiento, poder y religión: hacia una consideración de la mística teresiana como discurso filosófico", Investigaciones feministas, 11 (1), 2020, pp. 155-165.

- «La función ético-política de la autobiografía femenina renacentista: el caso del Libro de la vida de santa Teresa de Jesús», Araucaria, 23 (46), 2021, pp. 653-676.

- Discurso feminista colombiano preilustrado: la imagen femenina en la Vida de Sor Francisca de la Concepción», Revista Cultura \& Religión, XV (1), 2021, pp. 109-146.

Dirección electrónica: patricia.fernandez01@uam.es 